NBER WORKING PAPER SERIES

\title{
LONG-RUN DETERMINANTS OF INFLATION DIFFERENTIALS IN A MONETARY UNION
}

\author{
Filippo Altissimo \\ Pierpaolo Benigno \\ Diego Rodriguez Palenzuela \\ Working Paper 11473 \\ http://www.nber.org/papers/w11473
NATIONAL BUREAU OF ECONOMIC RESEARCH
1050 Massachusetts Avenue
Cambridge, MA 02138
June 2005

This paper does not reflect the views or opinions of the European Central bank but solely those of its authors. The authors are grateful to Kosuke Aoki, Philip lane and Roger Darmer for very helpful discussions and to Gianni Lombardo, Klaus Masuch, Roberto Motto and Sergio Nicoletti-Altimari as well as participants at the XVII Simposium Moneda y Crédito in Madrid and CEPR conference Designing a Macroeconomic Policy Framework for Europe in Barcelona for helpful comments. Any errors are the responsibility solely of the authors. The views expressed herein are those of the author(s) and do not necessarily reflect the views of the National Bureau of Economic Research.

(C2005 by Filippo Altissimo, Pierpaolo Benigno, Diego Rodriguez Palenzuela. All rights reserved. Short sections of text, not to exceed two paragraphs, may be quoted without explicit permission provided that full credit, including (C) notice, is given to the source. 
Long-Run Determinants of Inflation Differentials in a Monetary Union

Filippo Altissimo, Pierpaolo Benigno, Diego Rodriguez Palenzuela

NBER Working Paper No. 11473

July 2005

JEL No. E31, F41

\begin{abstract}
This paper analyzes the long-run determinants of inflation differentials in a monetary union. First, we aim at establishing some stylized facts relating the regional dispersion in headline inflation rates in the euro area as well as in the main components of the consumer price index. We find that a relatively large proportion of it occurs in the Service category of the EU's harmonized consumer price index (HICP). We then lay out a model of a monetary union with fully flexible prices, the long-run properties of which are analyzed. Our model departs in several respect from the BalassaSamuelson hypotheses. Our results are in contrast with the result that movements in the real exchange rate are mainly driven by regionally asymmetric productivity shocks in the traded sectors. Our results point instead to relative variations in productivity in the non-traded sector as the primary cause of price and inflation differentials, with shocks to productivity in the traded sector being largely absorbed by movements in the terms of trade in the regional economies. These shocks are also found to largely drive the variability of real wages at the country level.

$\begin{array}{lll}\text { Filippo Altissimo } & \text { Pierpaolo Benigno } & \text { Diego Rodriguez Palenzuela } \\ \text { European Central Bank } & \text { Department of Economics } & \text { European Central Bank } \\ \text { Kaiserstrasse 29 } & \text { New York University } & \text { Kaiserstrasse 29 } \\ \text { D-60311 Frankfurt am Main } & \text { 269 Mercer Street, } 7^{\text {th }} \text { Floor } & \text { D-60311 Frankfurt am Main } \\ \text { GERMANY } & \text { New York, NY 10003 } & \text { GERMANY } \\ \text { filippo.altissimo@ecb.int } & \begin{array}{l}\text { and NBER } \\ \text { pierpaolo.benigno@nyu.edu }\end{array} & \text { diego.rodriguez@ecb.int }\end{array}$
\end{abstract}




\section{Introduction}

The experience of a major transformation in the exchange rate regime associated with the launch of the euro has spurred much research aiming at understanding the scope for, magnitude and persistence of inflation differentials across the regions of a monetary union as well as their potential relevance for monetary policy making. The initial years of EMU coincided with a change in trend in the observed degree of dispersion in inflation rates across euro area countries. In the run-up to monetary union, inflation rates across member countries had largely converged. In the year 2000 the degree of dispersion across countries picked up somewhat and since then a non-negligible degree of dispersion across national inflation rates in euro area has been at times observed.

Early contributions in the literature ${ }^{1}$ aimed at accounting for the persistence of inflation differentials within a monetary union such as the euro area in terms of the relevance in this respect of the Balassa-Samuelson effect. ${ }^{2}$ Such an explanation based Balassa-Samuelson effect seemed appealing, at least prima facie, taking into account in particular that national inflation rates were highest in the fastest-growing economies such as Ireland, Greece and Spain. However, the focus on a single explanatory factor was gradually superseded by broader explanations ${ }^{3}$ in which the observed inflation differentials were accounted for by more complex interactions among various factors such as the presence of heterogeneity in regional market structures (e.g. the degree of market competition), the consequences of common and idiosyncratic regional shocks of both a supply and demand nature and the role of fluctuations in the regions' terms of trade to transmit and absorb the effects of shocks to fundamentals.

This paper aims at analyzing the determinants of inflation differentials in a monetary union both from an empirical and a theoretical dimension.

First, in order to motivate the theoretical investigation, we first present evidence on the statistical features of observed dispersion in headline inflation rates as well as in changes in the components of the consumer price index, ${ }^{4}$ based on the experience of most of the European Union countries conforming the euro area. Our descriptive exercise shows that there is still a sizeable dispersion of HICP inflation rates across euro area countries. In a sectorial decomposition of this dispersion, we find that most of it originates in the Service category of the HICP (although in some historical periods also the Energy category has significantly contributed to overall dispersion). This suggests that the main source of dispersion in countries' headline inflation rates is in those components of the HICP where non-traded goods are more intensely represented. We then use a dynamic factor model to analyze the sources of dispersion in countries inflation rates, decomposing the aggregate and sectorial measures of dispersion in, on the one hand, a common component - driven by common factors - and, on the other hand, an idiosyncratic component.

\footnotetext{
${ }^{1}$ See for instance De Grauwe et al (2000).

${ }^{2}$ See Balassa (1964) and Samuelson (1964).

${ }^{3}$ See Blanchard (2001) for an early dicussion in this respect.

${ }^{4}$ All data relating consumer prices, both relating headline inflation in the euro area, countries' consumer prices and subcomponents of the consumer price indes at the euro area and country levels, will refer to Eurostat's Harmonised Index of Consumer Prices (henceforth HICP).
} 
We find that the heterogeneous responses, across countries, to a change in the estimated common factor can account for a sizeable fraction of the dispersion in national inflation rates. This is particularly the case for the Non-Energy Industrial goods categories, even if the cross-country dispersion of the inflation rates of items in this category is relatively quite low. Moreover, this also applies particularly to the Services component of the HICP, which, importantly, is instead characterized by a relatively high level of dispersion. These results overall underline the large relative contribution that the observed persistence in regional inflation differentials in the Services component of the HICP make to overall persistence in observed headline inflation differentials across regions.

Second, we build a stylized model of a monetary union comprised of two regions, with a view to gauging the relative contributions in explaining the qualitatively features of the data of, on the one hand, innovations in the shocks and, on the other hand, structural differences in the regional economies. In each of the two regions of the model monetary union, two productive sectors are assumed, a traded and a non-traded goods sector. Each region is specialized in the production of a distinct, non-overlapping bundle of traded goods. The law of one price holds for each of the traded goods produced. Thus, consumer price and inflation differentials arise in the model as a consequence of movements in the relative prices of non-traded goods. This is the standard channel emphasized also by the trade literature on the Balassa-Samuelson effect.

Some distinct aspects of this model relative to the literature are described in the following.

One important feature is that capital is not mobile and that labour mobility within sectors of the same country can be imperfect for the introduction of imperfect substitutability between different varieties of sector-specific labour. This device generates wage differentials across sectors, which is a desirable feature from an empirical perspective (e.g. Ortega, 2003) and introduces an amplifying effect on the relative price movements in response to sectorial shocks. ${ }^{5}$

For the assumption of country specialization in the production of traded goods, terms of trade movement are critical for the transmission mechanism of shocks. As has been recently pointed out in the literature (Benigno and Thoenissen, 2003), a positive productivity gain in the tradable good sector has two counteracting effects on the overall price level, with upward pressure on the relative price of non-tradables offset by a worsening of the terms of trade. Which effect dominates depends on the relative values of the elasticities of substitution in consumption preferences between home and foreign tradables and the degree of labour mobility.

Interestingly, we show that the Balassa-Samuelson result -that movements in the real exchange rate are significantly affected by asymmetric shocks in the traded productivity- is modified and for realistic parametrizations of the model of limited empirical relevance. Our results point instead to relative variations in productivity in the non-traded sector as the primary cause of price and inflation differentials, with shocks to productivity in the traded sector being largely absorbed by movements in the terms of trade in the regional economies. These shocks are also found to drive the variability of wages at the cross-country level.

\footnotetext{
${ }^{5}$ Inter-regional mobility is not allowed in the model, even over the lung run.
} 
New insights on the explanation of real exchange rate movements emerge in our framework. Namely, a balanced (i.e. that affects both sectors) productivity shocks in one country may have a role in explaining real exchange rate movements or, in a monetary union, inflation differentials. In particular, we find that, for plausible parameter values, a balanced increase in productivity in one country has a negative and sizeable impact on the consumer price of the country relative to the rest of the area. Moreover, our framework permits that demand shocks play a role in generating long-term price or inflation differentials across countries.

The paper is structured as follows: Section 2 presents the descriptive statistics on euroarea inflation differentials and proposes a dynamic factor model decomposition of it. Section 3 presents the structure of the model. Section 4 characterizes the equilibrium and transition dynamics upon shocks in the model, under fully flexible prices. It also shows the long-run impact of permanent increases in the structural shocks. Section 5 presents the variance decomposition of key endogenous variables in the model as a function of the variance of the structural shocks. Section 6 closes the paper.

\section{Euro area inflation differentials}

This section addresses three empirical questions concerning the euro area economy. How sizable are the inflation differentials in the euro area in comparison to other currency areas? Are the inflation differentials in the euro area a sectorial phenomena, i.e. tradable versus non-tradable? Are the inflation differentials in the euro area the result of differentiated responses to common area-wide factors, or are they due to idiosyncratic (sector/country specific) factors?

A number of papers have recently provided empirical analysis of inflation differentials in the euro area. Alberola (2000) is one of the first analysis of post-EMU data specifically focusing on cross-country inflation differentials. Recently a more extensive review of empirical evidence and literature has been conducted by the ECB, (ECB, 2003). The latter work surveys a variety of measures of price and cost developments at the national level in EU-12 during the 1999-2002 period and explores different possible macroeconomic determinants. Here we maintain a narrower focus on which are the stylized statistical facts that are more relevant for our analysis. For this, we provide descriptive statistics as well as perform econometric analysis based on dynamic factor models.

The data used are based on the harmonized index of consumption prices (HICP). These data are harmonized indices of consumer prices for a basket of all goods and services consumed by a country, expenditure-weighted. We analyze seasonally adjusted data for the area as a whole and for ten individual countries (all euro countries except for Greece and Luxemburg), for the period from January 1990 to February 2004. Excluding Greece and Luxembourg reflects the fact that HICP data series for these countries are shorter than for the other countries in the sample. Both for the euro area and the individual countries HICP we considered the overall HICP inflation index as well as the five main subcomponents in the HICP, namely Services, Industrial Good 
excluding Energy, Energy, Processed Food and Unprocessed Food. ${ }^{6}$

To set notation, $\pi_{j, t}^{i}$ is the year on year growth rate of price in subindex $j$ of country $i$ and the aggregate euro area counterpart is $\pi_{j, t}^{\text {euro }}$. While $\pi_{t}^{i}$ denotes the overall inflation rate in country $i$ and $\pi_{t}^{\text {euro }}$ is the overall euro area inflation rate. The inflation differential between country $i$ and the euro area is denoted as:

$$
\delta_{i, t}=\left(\pi_{t}^{i}-\pi_{t}^{\text {euro }}\right)
$$

while the dispersion of inflation is measured by the root mean squared around the euro area average, as :

$$
\Delta_{t}=\left(\frac{\sum_{i=1}^{10} \delta_{i, t}^{2}}{10}\right)^{1 / 2} .
$$

The inflation differential between subindex $j$ in country $i$ and the euro area one is denoted as:

$$
\delta_{j, i, t}=\left(\pi_{j, t}^{i}-\pi_{j, t}^{e u r o}\right)
$$

while the dispersion of inflation in the sub-component $j$ is measured as:

$$
\Delta_{j, t}=\left(\frac{\sum_{i=1}^{10} \delta_{j, i, t}^{2}}{10}\right)^{1 / 2} .
$$

The overall dispersion $\Delta_{t}$ is not the weighted average of the sectorial dispersion given the nonlinearity of the transformation. We decompose the overall dispersion into the relative contribution of the different subcomponents. To this end, first, we assume that the sectorial country weights inside the HICP, $w_{j, i, t}$, are equal across countries, i.e. $w_{j, i, t}=w_{j, t} \forall i$, then we define the contribution of sector $j$ to the overall inflation dispersion as:

$$
\frac{w_{j} \times \Delta_{j, t}}{\sum_{j} w_{j} \times \Delta_{j, t}}
$$

The cross-country dispersion in inflation has been declining during the 90s across euro area as documented in Figures 1. Dispersion was above $4 \%$ in the early 90 s while it reached its minimum at $0.26 \%$ at the end of 1997 . After this point, the previous trend was inverted, starting to edge up again to around 1\% between 1998 and 2002. In early 2004 it stood at around $0.64 \%{ }^{7}$

Compared with the degree of dispersion observed within some individual euro area countries, inflation dispersion within the euro area remains relatively high. In particular, the recent degree of dispersion within the euro area is around twice the comparable measures computed across the German Länder, the Spanish Comunidades Autónomas and the Italian cities. On the contrary,

\footnotetext{
${ }^{6}$ The weights of the five subindexes in the euro area HICP index in 2004 are $0.41,0.31,0.08,0.12$ and 0.08 , respectively.

${ }^{7}$ This finding is slightly different from the one reported in ECB (2003), due to the fact that we considered the dispersion of the 10 indicated countries vis-à-vis the euro area while ECB (2003) considered also Greece and Luxemburg.
} 
the recent euro area inflation dispersion is quite comparable to the one measured among the 14 US metropolitan areas. The inflation divergence among US cities stayed remarkably constant at around 1 percent for many years. However the analogy is probably misleading, given that US cities are much smaller than EU nations, and their price indices tend to be more volatile.

Despite the possible similarities in the level of inflation dispersion between US and euro area, the high persistence of inflation differential is a characterizing feature of the euro area economy, as noted by Cecchetti, Mark and Sonora (2000). Indeed, in our data set the measured persistence of the inflation differential, $\delta_{j, i, t}$, is very close to the one of a unit root process on average across countries and sectors. ${ }^{8}$

The importance of sectorial pattern in explaining the overall dispersion is addressed in Figures 2-3. Figure 2 shows the dispersion of the year-on-year inflation rates in the euro area countries in the Services, Industrial Good Excluding Energy and Energy sectors together with the dispersion of the overall index. While Figure 3 presents the contribution of the sectors to the overall inflation dispersion.

Several conclusions can be drawn. First, all the components of inflation contributed to the very low dispersion observed in 1997-1998. Second, the increase on dispersion between 2000 and 2002 can mainly attributed to the dispersion in Services and Energy sectors. Third, Figures 2 shows that the dispersion in the Service sector has been almost always higher than the overall dispersion and its contribution has been increasing over time as indicated in Figure 3, also in line with the increase of the weight of this subcomponent inside the HICP index. Fourth, differently to the Services, the Industrial Good excluding energy index presents a low degree of dispersion and its overall importance is decreasing. Finally, differently from the common wisdom, the dynamic of the Energy subindex is a major source of overall dispersion. This is due both to the large volatility of this subindex but also to considerable heterogeneity in the countries' response to shocks.

Interpreting those results some cautionary remarks should be made. The HIPC is an index of final consumer prices for a basket of all goods and services consumed; so Industrial Good excluding energy price includes also the prices of (tradable) imported goods and a share of final sale services, such as the prices of any non-tradable marketing and other final consumption services; the services component included in the final Industrial good price might induce to overestimate the dispersion of this sector. On the contrary, this is not the case in the Services sector, where the value added deflator of Services almost entirely accounts for the final price of Services, as indicated by the input-output evidence produced by Sondergaard (2003) for some euro countries.

Finally, we address the last of the three questions stated at the outset - namely, whether the observed dispersion in inflation across euro area countries is due to different reaction to area-wide factors or the result of country/sectorial developments. To tackle this question we follow a similar approach to the one employed by Forni and Reichlin (2001) to decompose euro countries GDP growth into a European, a national, and a residual component. We estimate an approximate

\footnotetext{
${ }^{8}$ If we measure the persistence of the differential process by the largest autoregressive roots of a fitted ARMA model, it turns out that the largest autoregressive root is 0.981 on average across sectors and countries.
} 
dynamic factor model ${ }^{9}$ on the inflation differential which allows us to decompose the differential in each countries and sectors as:

$$
\delta_{j, i, t}=c_{j, i}+\Phi_{j, i}(L) \times u_{t}+\xi_{j, i, t}=\chi_{j, i, t}+\xi_{j, i, t}
$$

where the first term of the right hand side is the average dispersion over the sample (ideally nil), the second term captures the effect of common area wide shocks, $u_{t}$, which is allowed to propagate across countries and sectors with a differentiate dynamic, and the last term captures an idiosyncratic dynamic, mainly associated to country or sectorial specific developments. We grouped the first and second term into $\chi_{j, i, t}$.

The approximate dynamic factor models exploits the cross-section dimension of a large panel of time series to identify and estimates the part of the time series driven by few common shocks, $\chi_{j, i, t}$. To this end, in order to have proper estimates of the euro area common components in (1), we augmented the sixty time series on differential, $\delta_{j, i, t}$, with 193 monthly macro-economic time series related to the ten euro area countries considered. ${ }^{10}$ The estimation has been performed on the sample period 1993.01-2003.06. In line with the finding of similar exercises, the results points to the presence of strong commonalities among the 253 variables and the estimated common factors account on average of around $50 \%$ of the variance of the 253 variables. ${ }^{11}$

Having an estimate of the two components in (1), we can first ask how much of the historical dynamic of differentials is accounted by the identified area wide factors. The table below reports the average across countries of the share of variance of the differentials, $\delta_{j, i, t}$, accounted by common shocks, both for the overall index and for the individual subindexes.

\begin{tabular}{cccccc}
\hline \hline Overall & Services & Industrial & Energy & Proc. Food & Unproc. Food \\
\hline 0.66 & 0.58 & 0.67 & 0.52 & 0.65 & 0.42 \\
\hline \hline
\end{tabular}

It turns out that the Energy and the Services sector are the ones with the large idiosyncratic components, while the Industrial Good excluding Energy and the Processed Food sectors are the most common ones.

The importance of the common factors is also clear from Figure 4-7, where we show how the dispersion in inflation can be decomposed into the part attributed to the common factor, $\chi_{j, i, t}$, and a remaining one, associated to the idiosyncratic part. Figure 4 presents the cross-country dispersion of the overall HICP and its decomposition. The common part is clearly responsible for the large part of the observed dispersion. The idiosyncratic part has a nil contribution to overall dispersion from 1994 to 2000, but it contributes positively to dispersion from 2000 onward. The

\footnotetext{
${ }^{9}$ See Stock and Watson (1999) and Forni, Hallin, Lippi and Reichlin (2000).

${ }^{10}$ The data considered are, inter alia, main and sectoral industrial production indexes, consumer and producer surveys, producer prices index, financial quantities, interest rates, trade statistics. The data has been seasonally adjusted and transformed to be stationary.

${ }^{11}$ The estimation procedure is based on the principal component decomposition of the variance-covariance matrix of the data. The estimation indicates the presence of five static factors in the models.
} 
Service sector presents a behavior similar to the overall index with large part of its dispersion explained by country-specific reaction to common shocks. The increase in dispersion since 2000 is mainly associated to the common factor; even if idiosyncratic elements contributed positively both during 2000 and 2002. In the Industrial sector the commonality is even more striking, however it should be noted that the dispersion in this sector is relative low. By contrast, in the case of Energy prices most of the dispersion is due to presence of idiosyncratic factors, see Figure 7.

To conclude, the inflation differentials in the euro area are relevant and persistent. Our proxy of the non-tradable sector, namely the Services sector seems to make a particularly strong contribution to dispersion; this related to both the effects of common as well as the idiosyncratic factors behind the Services component. By contrast, the dispersion in our proxy of the price index of tradable goods - namely industrial goods excluding energy - is relatively limited. Finally, a tentative overall conclusion from our attempt to understand the source of inflation differentials would indicate that they are largely associated to different responses of the ten euro area economies to common, area-wide shocks.

In the next section, we build a model in which the dispersion of prices at the consumer level arises because of dispersion of prices in the non-traded sector and we analyze which shocks are most responsible for generating such a dispersion. We focus on the long-run properties of the model with no aim then at addressing the issue of persistence. ${ }^{12}$

\section{The Model}

Observed dispersion in the consumer price level across regions or countries in a monetary union may be decomposed in its shorter-term and longer-term components, with the latter capturing the persistency in price level and inflation differentials. The focus of our paper is on this second component relating to long-lasting price level and inflation differentials across countries. For this, we lay out a tractable model of a monetary union, aimed at analyzing the relative contributions of various structural shocks to explaining the long-run component of the dispersion in prices at the consumer level across countries.

The model monetary union is comprised of two countries of equal population size. Consumption preferences depend on non-traded and traded goods. Each country is specialized in the production of a distinct and non-overlapping bundle of tradable goods. Financial markets are complete within and across countries. Labor is immobile across countries but imperfectly mobile within the sectors of a country. Prices are flexible in all sectors of the economy. The law of one price holds in the traded sector and PPP holds at the level of traded goods. The model permits to study deviations from PPP at the consumer level which arise as a consequence of movements in the relative prices of non-traded goods.

Our model is closely related to recent open-economy models, like Obstfeld and Rogoff (2000)

\footnotetext{
${ }^{12}$ This is the focus of a related work, Altissimo et al. (2004).
} 
who introduces non-traded goods in stochastic models with sticky prices. Benigno and Thoenissen (2003) use a similar model to study the real exchange rate behavior of UK with respect to the Euro area with the purpose of analyzing whether supply shocks can account for the real exchange rate appreciation in the late nineties.

In reference to the recent literature on monetary unions our model is closely related to Duarte and Wolman $(2002,2003)$. Their analysis is richer in two respects: first, they allow also for the presence of producers' price discrimination when selling same traded good in different countries; second, they endow fiscal policy rules with a non-trivial role in the reduction or amplification of inflation differentials. This results from their assumption that lump-sum taxes are not available to governments. In particular, Duarte and Wolman (2002) find that their model can deliver more inflation dispersion following productivity shocks than what is observed in the data, while they find that government spending shocks give rise to a negligible degree of dispersion. By contrast to this analysis, our approach is limited to the case in which only lump-sum taxes are available.

Andrés et al. (2003) analyzes a model in which only traded goods exist and in which price discrimination across countries - made possible by differences in the degree of market competition across the countries - is allowed for. They show that their model can account for sizeable inflation differentials and that the driving force of the price dispersion in the traded sector originates more from the mechanism of price discrimination rather than on price rigidity. Angeloni and Ehrmann (2004) present a more stylized 12-country model of the euro area and in particular they focus on the importance of assuming a role for inflation lags in the aggregate supply equation. They find that this additional source of inflation persistence is important in driving up inflation dispersion in the currency area. There are other papers that have analyzed monetary models of currency areas, as Benigno (2004), Beetsma and Jensen (2004) and Lombardo (2004). However these models do not allow for price dispersion at the consumer level and mainly focus on the role of the terms of trade in stabilizing asymmetric shocks, when prices are sticky.

\subsection{Households}

We consider a model of a currency area composed by two countries, Home $(H)$ and Foreign $(F)$. Each country is populated by a measure one of households. A generic household $j$ belonging to either country $H$ or $F$ maximizes the following utility function:

$$
U_{t}^{j} \equiv \mathrm{E}_{t} \sum_{s=t}^{\infty} \beta^{s-t}\left[U\left(C_{s}^{j}\right)-V\left(L_{s}^{j}\right)\right],
$$

where $\mathrm{E}_{t}$ denotes the expectation conditional on the information set at date $t$ and $\beta$ is the intertemporal discount factor, with $0<\beta<1$. Households derive utility from consumption and disutility from supplying hours of work.

There are two classes of goods in both economies: traded and non-traded goods. Each country produces a measure one of goods, a fraction $\gamma\left(\gamma^{*}\right.$ in region $\left.F\right)-$ with $0<\gamma, \gamma^{*}<1$ - is composed

by traded goods. The remaining fractions are non-traded goods. The consumption index $C_{t}^{j}$ in 
region $H$ is defined as a Dixit-Stiglitz aggregator of indexes of traded, $C_{T}^{j}$, and non-traded goods, $C_{N}^{j}$, as it follows

$$
C^{j} \equiv\left[\omega^{\frac{1}{\varphi}}\left(C_{T}^{j}\right)^{\frac{\varphi-1}{\varphi}}+(1-\omega)^{\frac{1}{\varphi}}\left(C_{N}^{j}\right)^{\frac{\varphi-1}{\varphi}}\right]^{\frac{\varphi}{\varphi-1}}
$$

where $\varphi$ is the elasticity of substitution between the bundles $C_{T}$ and $C_{N}$ with $\varphi>0$ while $\omega$ denotes the share of traded goods in the general consumption basket, with $0<\omega<1$. (This share may be different for households in region $F$ and it will be denoted by $\omega^{*}$.) The traded goods are non-homogenous and differentiated in consumption preferences. They are also produced with different technologies. In particular the index $C_{T}^{j}$ is defined as a Dixit-Stiglitz aggregator of the bundles of home-produced traded goods, $C_{H}^{j}$, and foreign-produced traded goods, $C_{F}^{j}$, in the following way

$$
C_{T}^{j} \equiv\left[n^{\frac{1}{\theta}}\left(C_{H}^{j}\right)^{\frac{\theta-1}{\theta}}+(1-n)^{\frac{1}{\theta}}\left(C_{F}^{j}\right)^{\frac{\theta-1}{\theta}}\right]^{\frac{\theta}{\theta-1}},
$$

where $\theta$, with $\theta>0$, is the elasticity of substitution between the bundles $C_{H}^{j}$ and $C_{F}^{j}$ and $n$, with $0<n<1$, denotes the share of home-produced traded goods in the overall index of traded goods. In the foreign economy $n^{*}$, with $0<n^{*}<1$, denotes the share of foreign-produced traded goods in the overall basket of traded goods. The consumption bundles $C_{H}^{j}$ and $C_{F}^{j}$ are composed by the continuum of differentiated traded goods produced respectively in region $H$ and $F$ and are defined as

$$
C_{H}^{j} \equiv\left[\gamma^{-\frac{1}{\sigma}} \int_{0}^{\gamma} c^{j}(h)^{\frac{\sigma-1}{\sigma}} d h\right]^{\frac{\sigma}{\sigma-1}}, \quad C_{F}^{j} \equiv\left[\gamma^{*-\frac{1}{\sigma}} \int_{0}^{\gamma^{*}} c^{j}(f)^{\frac{\sigma-1}{\sigma}} d f\right]^{\frac{\sigma}{\sigma-1}},
$$

where $\sigma>1$ is the elasticity of substitution among the differentiated goods. Similarly, $C_{N}^{j}$ is the home consumption index of the continuum of differentiated non-traded goods:

$$
C_{N}^{j} \equiv\left[(1-\gamma)^{-\frac{1}{\sigma}} \int_{\gamma}^{1} c_{N}^{j}(h)^{\frac{\sigma-1}{\sigma}} d h\right]^{\frac{\sigma}{\sigma-1}}
$$

with the same elasticity of substitution $\sigma$. In country $F, \gamma^{*}$ replaces $\gamma$ in the consumption bundles of non-traded goods.

Given the above consumption indices, we can derive the appropriate price indices. With respect to the general consumption index, we obtain the consumption-based price index $P$

$$
P=\left[\omega\left(P_{T}\right)^{1-\varphi}+(1-\omega)\left(P_{N}\right)^{1-\varphi}\right]^{\frac{1}{1-\varphi}}
$$

where $P_{T}$ and $P_{N}$ are given by

$$
P_{T}=\left[n\left(P_{H}\right)^{1-\theta}+(1-n)\left(P_{F}\right)^{1-\theta}\right]^{\frac{1}{1-\theta}},
$$




$$
P_{N}=\left[(1-\gamma)^{-1} \int_{\gamma}^{1} p_{N}(h)^{1-\sigma} d h\right]^{\frac{1}{1-\sigma}}
$$

while $P_{H}$ and $P_{F}$ are given by

$$
P_{H}=\left[\gamma^{-1} \int_{0}^{\gamma} p(h)^{1-\sigma} d h\right]^{\frac{1}{1-\sigma}}, \quad P_{F}=\left[\gamma^{*-1} \int_{0}^{\gamma^{*}} p(f)^{1-\sigma} d f\right]^{\frac{1}{1-\sigma}}
$$

where $p(h), p(f), p_{N}(h)$ are respectively the prices in the common currency faced by households in country $H$ for a generic home-produced traded good, a foreign-produced traded good and a domestic non-traded good. Similar indices are derived for country $F$ with the appropriate modifications of the respective shares. Prices faced by foreign consumers are denoted with asterisks.

Given the consumption-based price indexes the generic home consumer $j$ has the following demand of each of the home-produced traded goods

$$
c^{j}(h)=\frac{n \omega}{\gamma}\left(\frac{p(h)}{P_{H}}\right)^{-\sigma}\left(\frac{P_{H}}{P_{T}}\right)^{-\theta}\left(\frac{P_{T}}{P}\right)^{-\varphi} C^{j},
$$

for $0 \leq h<\gamma$; of each of the foreign-produced traded goods

$$
c^{j}(f)=\frac{(1-n) \omega}{\gamma^{*}}\left(\frac{p(f)}{P_{F}}\right)^{-\sigma}\left(\frac{P_{F}}{P_{T}}\right)^{-\theta}\left(\frac{P_{T}}{P}\right)^{-\varphi} C^{j},
$$

for $0 \leq f<\gamma^{*}$ and of each of the home-produced non-traded goods

$$
c_{N}^{j}(h)=\frac{1-\omega}{1-\gamma}\left(\frac{p_{N}(h)}{P_{N}}\right)^{-\sigma}\left(\frac{P_{N}}{P}\right)^{-\varphi} C^{j}
$$

for $\gamma \leq h \leq 1$. Similar demands hold in the foreign economy.

Households get disutility from supplying labor to all the firms operating in their country of residence. In particular the function $V($.$) is increasing and convex in an index of labor L^{j}$. Each firm uses a specific labor factor and each household can supply all the varieties of labor used in the country to produce the continuum of traded and non-traded goods. In particular each household supplies a measure one of labor varieties, of which a fraction $\gamma$ will be employed in the traded sector ( $\gamma^{*}$ is the respective fraction in the foreign economy) and the remaining respective fractions in the non-traded sector. In particular we assume that $L^{j}$ is a Dixit-Stiglitz aggregator of labor indices $L_{T}$ and $L_{N}$ in the traded and non-traded sectors, respectively, as it follows

$$
L^{j} \equiv\left[\gamma^{\frac{1}{\phi}}\left(L_{T}^{j}\right)^{\frac{\phi-1}{\phi}}+(1-\gamma)^{\frac{1}{\phi}}\left(L_{N}^{j}\right)^{\frac{\phi-1}{\phi}}\right]^{\frac{\phi}{\phi-1}}
$$

where $\phi>0$ is the elasticity of substitution between labor in the traded and non-traded sector 
and $L_{T}^{j}$ and $L_{N}^{j}$ are composite index of the continuum of varieties supplied in both sectors

$$
L_{T}^{j} \equiv\left[\gamma^{-\frac{1}{v}} \int_{0}^{\gamma} l_{T}^{j}(i)^{\frac{v-1}{v}} d i\right]^{\frac{v}{v-1}}, \quad L_{N}^{j} \equiv\left[(1-\gamma)^{-\frac{1}{v}} \int_{\gamma}^{1} l_{N}^{j}(i)^{\frac{v-1}{v}} d i\right]^{\frac{v}{v-1}}
$$

where $v>0$ is the elasticity of substitution between varieties of labor within a sector. In contrast with standard models of traded and non-traded production, we are not necessarily assuming that labor is perfectly substitutable and mobile across sectors and instead we allow for wage differentiation across varieties of labor. The case of perfect substitutability, and perfect labor mobility, is nested under the assumption that both $\phi, v \rightarrow \infty$. In general, given wages $w_{T}(i)$ and $w_{N}(i)$ specific to the generic variety $i$ in the respective traded and non-traded sector, we can write the following wage indexes associated with the above defined labor indices

$$
\begin{gathered}
W=\left[\gamma W_{T}^{1-\phi}+(1-\gamma) W_{N}^{1-\phi}\right]^{\frac{1}{1-\phi}} \\
W_{T}=\left[\gamma^{-1} \int_{0}^{\gamma} w_{T}^{1-v}(i) d i\right]^{\frac{1}{1-v}}, \quad W_{N}=\left[(1-\gamma)^{-1} \int_{\gamma}^{1} w_{N}^{1-v}(i) d i\right]^{\frac{1}{1-v}} .
\end{gathered}
$$

Given the relative wages and the choice of $L^{j}$, we can then characterize the household's labor decisions in the following way

$$
l_{T}^{j}(h)=\left(\frac{w_{T}(h)}{W_{T}}\right)^{-v}\left(\frac{W_{T}}{W}\right)^{-\phi} L^{j}, \quad l_{N}^{j}(i)=\left(\frac{w_{N}(i)}{W_{N}}\right)^{-v}\left(\frac{W_{N}}{W}\right)^{-\phi} L^{j},
$$

for each variety of labor supplied to a generic firm in a traded and non-traded sector, respectively.

Each household faces the following flow budget constraint

$$
B_{t}^{j} \leq A_{t}^{j}+W_{t} L_{t}^{j}+\Pi_{t}^{j}-P_{t} C_{t}^{j}+T_{t}^{j}
$$

where $A_{t}^{j}$ represents the beginning-of-period wealth that includes the bonds carried from the previous period. $B_{t}^{j}$ is the end-of period portfolio that includes a wide selection of instruments that pay in each contingency that occurs. In particular they pay $A_{t}$ in the particular contingency at date $t$. As of time $t-1, A_{t}$ is a random variable whose realization depends on the state of nature at time $t$.

Here it is assumed that there are complete financial market which implies that there exists a unique discount factor $Q_{t, t+1}$ with the property that the price in period $\mathrm{t}$ of a portfolio with random value $A_{t+1}$ is

$$
B_{t}=E_{t}\left[Q_{t, t+1} A_{t+1}\right]
$$

where $E_{t}$ denotes the expectation conditional on the state of nature at date $t$. In particular we define the short-term interest rate in the following way, as the price of the portfolio that delivers 
one unit of currency in each contingency that occur one-period ahead, i.e.

$$
\frac{1}{1+i_{t}}=E_{t}\left[Q_{t, t+1}\right]
$$

In (2), $\Pi_{t}$ are aggregate profits of all the firms within a country. Profits are risk shared across households. $T_{t}^{j}$ are transfers from the government to household $j$. The economy is a cashlesslimiting monetary economy as discussed in Woodford (2003). The flow budget constraint of the consumer can be written as

$$
E_{t}\left[Q_{t, t+1} A_{t+1}^{j}\right] \leq A_{t}^{j}+W_{t} L_{t}^{j}+\Pi_{t}^{j}-P_{t} C_{t}^{j}+T_{t}^{j}
$$

and the consumer's problem is further subject to the following borrowing limit condition in each contingency and date that the consumer faces.

$$
A_{t+1}^{j} \geq-\sum_{s=t+1}^{\infty} E_{t+1} Q_{t+1, s}\left\{W_{s} L_{s}^{j}+\Pi_{s}^{j}+T_{s}^{j}\right\}>-\infty .
$$

The borrowing limit condition together with the flow budget constraint imply the standard intertemporal budget constraint

$$
\sum_{s=t}^{\infty} E_{t} Q_{t, s}\left[P_{s} C_{s}^{j}\right] \leq A_{t}^{j}+\sum_{s=t}^{\infty} E_{t} Q_{t, s}\left[W_{s} L_{s}^{j}+\Pi_{s}^{j}+T_{s}^{j}\right] .
$$

Given the above decisions on how to allocate consumption and labor across all the varieties, the household $j$ chooses the optimal path of the consumption index $C_{t}$ and labor index $L_{t}$ at all times and contingencies to maximize its utility under the intertemporal budget constraint. In particular the set of optimality conditions can be described by the set of Euler conditions

$$
\frac{U_{c}\left(C_{t}^{j}\right)}{U_{c}\left(C_{t+1}^{j}\right)}=\frac{\beta}{Q_{t, t+1}} \frac{P_{t}}{P_{t+1}}
$$

for each state of nature at time $t+1$ looking ahead from time $t$. By choosing appropriately the distribution of initial state-contingent wealth, complete markets assure that consumption is perfectly equalized within households belonging to a country. Moreover, across countries, the ratio of marginal utilities of consumption is proportional to the ratio of consumer prices:

$$
\frac{U_{c}\left(C_{t}\right)}{U_{c}\left(C_{t}^{*}\right)}=\varsigma \frac{P_{t}}{P_{t}^{*}}
$$

for a positive factor of proportionality $\varsigma>0$ which again depends on the initial wealth distribution. As shown by Backus and Smith (1993), under the assumption of complete financial markets, consumer-price differentials directly translate into consumption differentials, so that a country 
which experiences an increase in its consumer price level relative to another country should experience a fall in its own consumption relative to the other country. This complete-market assumption is a convenient simplification but it comes at a cost of neglecting wealth distribution as an important channel through which price and inflation differentials can propagate into the economy and be amplified.

Real wages, computed using the general price and wage indices, are equated to the marginal rate of substitution between the labor index $L$ and the consumption index $C$ as

$$
\frac{W_{t}}{P_{t}}=\frac{V_{l}\left(L_{t}\right)}{U_{c}\left(C_{t}\right)}
$$

Finally the last optimality condition is the exhaustion of the intertemporal budget constraint, i.e. (5) holds with equality at all times.

\subsection{Firms}

Regarding the supply side of the economy, we indeed assume that there is a continuum of firms, of measure one, which is producing the continuum of goods. In particular a fraction $\gamma\left(\gamma^{*}\right.$ in the foreign economy) is producing traded goods, while the remaining fractions are producing nontraded goods. Taking as representative the home economy, a generic firm producing in the traded sector is using the following technology $y^{T}(h)=A_{T} f(l(h))$, where $A_{T}$ is a country- and sectorspecific technological shock and $f($.$) is a standard concave production function in the specific$ variety of labor used in the production of good $h .{ }^{13}$ In the non-traded sector the technology is given by $y^{N}(h)=A_{N} f(l(h))$ for a generic firm $h$ in the non-traded sector. Firms in both sectors are monopolist and set their prices considering the overall demand of their goods. In the traded sector, we assume that there is no price discrimination and that all the consumers of the area face the same price for the same variety of goods. In particular in the traded sector a generic firm $h$ faces the following demand

$$
y^{T}(h)=\frac{n \omega}{\gamma}\left(\frac{p(h)}{P_{H}}\right)^{-\sigma}\left(\frac{P_{H}}{P_{T}}\right)^{-\theta}\left(\frac{P_{T}}{P}\right)^{-\varphi} C+\frac{n^{*} \omega^{*}}{\gamma}\left(\frac{p(h)}{P_{H}}\right)^{-\sigma}\left(\frac{P_{H}}{P_{T}^{*}}\right)^{-\theta}\left(\frac{P_{T}^{*}}{P^{*}}\right)^{-\varphi} C^{*}
$$

In the non-traded sector, a generic firm faces the following demand

$$
y^{N}(h)=\frac{1-\omega}{1-\gamma}\left(\frac{p_{N}(h)}{P_{N}}\right)^{-\sigma}\left[\left(\frac{P_{N}}{P}\right)^{-\varphi} C_{N}+G\right]
$$

where in particular $G$ is an exogenous country-specific government-purchase shock that affects only the demand of non-traded goods. Period profits for a generic firm $h$ in the traded sector are

\footnotetext{
${ }^{13}$ When $f($.$) has decreasing return to scale with respect to labor, we are implicitly assuming that there is a fixed$ factor of production, capital, which is not mobile across sectors.
} 
given by

$$
\pi_{T, t}=\left[\left(1-\tau_{T, t}\right) p_{t}(h) y_{t}^{T}(h)-w_{t}(h) l_{t}(h)\right],
$$

where $\tau_{T, t}$ is a sectorial country-specific time-varying proportional tax on sales in the traded sector, $p_{t}(h)$ denotes the price of the firm $h$ chosen at date $t$ and $y_{t}^{T}(h)$ is the total demand of firm $h$ at time $t$. As standard in models with monopolistic competition, profit maximization leads to the condition that prices are set as mark-up over nominal marginal costs

$$
p_{t}(h)=\mu_{T, t} M C_{t}^{T}(h),
$$

where

$$
\mu_{T, t} \equiv \frac{\sigma}{\left(1-\tau_{T, t}\right)(\sigma-1)}
$$

and the nominal marginal cost of firm $h$ are given by

$$
\begin{aligned}
M C_{t}^{T}(h) & \equiv \frac{w_{T, t}(h)}{f^{\prime}\left(f^{-1}\left(y_{t}^{T}(h) / A_{T, t}\right)\right) A_{T, t}} \\
& =\mu_{T, t} W_{t}\left(\frac{W_{T, t}}{W_{t}}\right)^{1-\frac{\phi}{v}}\left(\frac{f^{-1}\left[\left(y_{t, s}^{T}(h) / A_{T, t}\right]\right.}{L_{t}}\right)^{-\frac{1}{v}} \frac{1}{f^{\prime}\left(f^{-1}\left(y_{t}^{T}(h) / A_{T, t}\right)\right) A_{T, t}}
\end{aligned}
$$

All firms within a sector set the same price. It follows that the supply schedule in the traded sector of the domestic economy implies that

$$
1=\mu_{T, t} \frac{P_{t}}{P_{T, t}} \frac{P_{T, t}}{P_{H, t}} \frac{V_{l}\left(L_{t}\right)}{U_{c}\left(C_{t}\right)}\left(\frac{l_{T, t}}{L_{t}}\right)^{-\frac{1}{\phi}} \frac{1}{f^{\prime}\left(l_{T, t}\right) A_{T, t}} .
$$

As well, we obtain that in the traded sector of country $F$

$$
1=\mu_{T, t}^{*} \frac{P_{t}^{*}}{P_{T, t}^{*}} \frac{P_{T, t}^{*}}{P_{F, t}} \frac{V_{l}\left(L_{t}^{*}\right)}{U_{c}\left(C_{t}^{*}\right)}\left(\frac{l_{T, t}^{*}}{L_{t}^{*}}\right)^{-\frac{1}{\phi}} \frac{1}{f^{\prime}\left(l_{T, t}^{*}\right) A_{T, t}} .
$$

In the non-traded sectors, respectively in country $H$ and $F$, we obtain that

$$
\begin{aligned}
& 1=\mu_{N, t} \frac{P_{t}}{P_{N, t}} \frac{V_{l}\left(L_{t}\right)}{U_{c}\left(C_{t}\right)}\left(\frac{l_{N, t}}{L_{t}}\right)^{-\frac{1}{\phi}} \frac{1}{f^{\prime}\left(l_{N, t}\right) A_{N, t}}, \\
& 1=\mu_{N, t}^{*} \frac{P_{t}^{*}}{P_{N, t}^{*}} \frac{V_{l}\left(L_{t}^{*}\right)}{U_{c}\left(C_{t}^{*}\right)}\left(\frac{l_{N, t}^{*}}{L_{t}^{*}}\right)^{-\frac{1}{\phi}} \frac{1}{f^{\prime}\left(l_{N, t}^{*}\right) A_{N, t}^{*}},
\end{aligned}
$$

where $\mu_{T, t}^{*}, \mu_{N, t}$ and $\mu_{N, t}^{*}$ have been appropriately defined. 


\subsection{Fiscal and Monetary Policies}

Each country has its own fiscal authority while there is a single monetary policymaker for the whole area. In each region, the government raises revenues from the distortionary sale taxes to finance the expenditure for domestic non-traded goods. Moreover, lump-sum taxes are available to balance the budget in each period. It follows that

$$
\begin{aligned}
0= & \int_{\gamma}^{1} p_{N, t}(h) g_{t}(h) d h+\int_{0}^{1} T_{t}^{j} d j-\tau_{N, t} \int_{\gamma}^{1} p_{N, t}(h) y_{t}^{N}(h) d h \\
& -\tau_{T, t} \int_{0}^{\gamma} p_{t}(h) y_{t}^{T}(h) d h
\end{aligned}
$$

for country $H$ while

$$
\begin{aligned}
0= & \int_{\gamma^{*}}^{1} p_{N, t}^{*}(f) g_{t}^{*}(f) d f+\int_{0}^{1} T_{t}^{* j} d j-\tau_{N, t}^{*} \int_{\gamma^{*}}^{1} p_{t}^{N *}(f) y_{N, t}^{*}(f) d f \\
& -\tau_{T, t}^{*} \int_{0}^{\gamma^{*}} p_{t}^{*}(f) y_{t}^{*}(f) d f
\end{aligned}
$$

for country $F$, where $T_{t}^{* j}$ and $T_{t}^{j}$ are lump-sum transfers to households in countries $H$ and $F$ respectively. Given the full flexibility of prices monetary policy is just needed for nominal anchor.

The Appendix at the end describes in details the solution to the model.

\section{Equilibrium price differentials}

We can write the ratio of the CPI prices of the two countries in the following way

$$
\frac{P_{t}}{P_{t}^{*}}=\frac{P_{T, t}}{P_{T, t}^{*}} \frac{\left[\omega+(1-\omega) T_{N, t}^{1-\varphi}\right]^{\frac{1}{1-\varphi}}}{\left[\omega^{*}+\left(1-\omega^{*}\right) T_{N, t}^{* 1-\varphi}\right]^{\frac{1}{1-\varphi}}}
$$

where we have defined the relative price of non-traded with respect to traded goods in each country as $T_{N} \equiv P_{N} / P_{T}$ and $T_{N}^{*} \equiv P_{N}^{*} / P_{T}^{*}$. The ratio of the tradeable goods prices is instead given by

$$
\frac{P_{T, t}}{P_{T, t}^{*}}=\frac{\left[n P_{H, t}+(1-n) P_{F, t}\right]^{\frac{1}{1-\theta}}}{\left[n^{*} P_{F, t}^{*}+\left(1-n^{*}\right) P_{H, t}^{*}\right]^{\frac{1}{1-\theta}}} .
$$

There can be several possible ways through which differences in consumer prices can arise among countries. One obvious reason has to do with the different composition of the consumption indices, due to differences in tastes. This can happen either because there can be home bias in the consumption of traded good, so that $n^{*} \neq 1-n$ or because the share of traded goods in the overall consumption basket can vary across countries, $\omega \neq \omega^{*}$. Heterogeneity in consumption preferences can be a source of consumer-price differentials even if the prices of all the goods, 
traded and non-traded, are equalized across countries. Conversely, even if tastes are similar, price differentials at the single good level can produce differential at the consumer-price level. The above decomposition shows that this can happen either because of deviations from the law of one price for traded goods or because relative price of non-traded goods can vary across countries.

The issue of explaining consumer price differential in a currency area is closely related to a long-lasting puzzle in the international finance literature: the PPP puzzle and the related literature on real exchange rate behavior. ${ }^{14}$ Using the above decomposition, Engel (1999) has studied the US real exchange rate relative to several countries and shown that its variability can be accounted mostly by the variability of the deviations from the law of one price for traded goods relative to the variability of the relative price of non-traded goods. With multiple currencies, firms might set their prices sticky in the currency of the buyer, hence protecting consumers from fluctuations of the exchange rate. In this way deviations from the law of one price for traded goods reflect mostly fluctuations of the nominal exchange rate. This interpretation is naturally absent in a currency area, since there is no reason to protect prices from fluctuations of the nominal exchange rate. ${ }^{15}$

However, a unique currency does not exclude the possibility for firms to price discriminate across different markets (countries) due to different degrees of competition in the markets or structural characteristics.

Moreover, even if firms do not price discriminate and markets are characterized by similar structures and degrees of competition, there can be price deviations for traded goods that enter the consumption basket, stemming from the fact that traded goods usually carry some non-traded components (e.g. distribution costs) before reaching the consumer markets. ${ }^{16}$ Sondergaard (2003) using input-output tables for France, Italy and Spain has shown that the traded sector relies more than others on intermediate inputs produced by other sectors in the economy; in particular total inputs from other sectors account for 60 percent of gross output in the traded sector. Movements in the prices of non-traded goods that enter in the production or transportation of traded goods can be an important source of price dispersion for traded goods at the consumer level. Our evidence shows that inflation dispersion in the traded sector is much lower than in the nontraded sector, which suggests that in any case differences in the relative price of non-traded goods can be much more important in explaining the consumer price differential.

In this work, we choose not to model any price differential in the traded sector to get more

\footnotetext{
${ }^{14}$ See Rogoff (1996).

${ }^{15}$ A puzzling finding of Engel (1999) is that the importance of the relative price of traded goods in explaining the variability of the real exchange rate is robust across the fixed exchange rate period of Bretton Woods and the following floating exchange rate period. This decomposition holds in general also for developing economies, as in the case of Mexico studied by Engel (2001). However in this case Mendoza (2000) has shown that during periods of fixed-exchange rate regime movements in the relative price of non-traded goods are dominant in explaining real exchange rate volatility. In relation to the debate on whether deviations from the law of one price for tradeable goods originate from local currency pricing, works by Obstfeld and Rogoff (2000) and Campa and Goldberg (2002) have emphasized that the pass-through of the exchange rate at the border level can be high.

${ }^{16}$ The importance of distribution sectors in explaining differential at the consumer-price leve has been emphasized by Burstein et al. (2003) and Corsetti and Dedola (2004).
} 
insight on what we believe can be a stronger channel. ${ }^{17}$ We assume that there is no price discrimination and that $P_{H}=P_{H}^{*}$ and $P_{F}=P_{F}^{*}$ at all times. We also assume perfect symmetry across countries and sectors and set $\omega=\omega^{*}=\gamma=\gamma^{*}$ and $n=n^{*}=1 / 2$. It further follows that $P_{T}=P_{T}^{*}$. In the appendix, we solve the model by taking a log-linear approximation to the relevant structural equilibrium conditions around a deterministic steady state in which the shocks to markups, productivity and government expenditures, i.e. $\mu_{T, t}, \mu_{T, t}^{*}, \mu_{N, t}, \mu_{N, t}^{*}, A_{T, t}, A_{T, t}^{*}, A_{N, t}, A_{N, t}^{*}$, $G_{t}, G_{t}^{*}$, are such that $\bar{\mu}_{T}=\bar{\mu}_{T}^{*}=\bar{\mu}_{N}=\bar{\mu}_{N}^{*}=\bar{\mu}$ and $\bar{A}_{T}=\bar{A}_{T}^{*}=\bar{A}_{N}=\bar{A}_{N}^{*}=\bar{A}, \bar{G}=\bar{G}^{*}=0$. In a log-linear approximation around this steady state the consumer-price differential is proportional to the non-traded goods price differential (all in logs)

$$
\begin{aligned}
\ln P_{t}-\ln P_{t}^{*} & =(1-\gamma)\left(\hat{T}_{N, t}-\hat{T}_{N, t}\right) \\
& =(1-\gamma)\left(\ln P_{N, t}-\ln P_{N, t}^{*}\right),
\end{aligned}
$$

where hat variables represent log-deviations of the respective variable from the steady state.

The most popular and often advocated reason for why there can be long-lasting departures from PPP originating from non-traded goods prices is due to Balassa (1964) and Samuelson (1964). According to this view, countries that experience higher productivity growth in the traded sector will also show higher consumer prices. The reason is that productivity growth in the traded sector translates into an increase in the overall wage in the economy, since prices of traded goods are tied internationally and there is perfect labor mobility. In the non-traded sector, firm will increase their prices since costs have increased and there are no benefits from productivity gains.

There are several assumptions needed to get this result, as discussed in Froot and Rogoff (1995): mobility of labor and capital across sectors and mobility of capital internationally, constant returns to scale in the mobile factors and exogenous world real interest rate. Indeed, we cannot expect our model to display the Balassa-Samuelson features since capital is constant in each sector and labor is not perfectly mobile. Moreover, as shown in recent works by Benigno and Thoenissen (2003), Cova (2003), Duarte and Wolman (2003), Fitzgerald (2002), MacDonald and Ricci (2002), the assumption of homogenous traded-good market is critical for the BalassaSamuelson result to hold. In our model, each country is specialized in the production of a bundle of traded goods. When the traded sector of a country is subject to a productivity shock, prices of home-produced traded goods can fall with respect to foreign-produced traded goods and terms of trade worsen. In this case movements in terms of trade can absorb the productivity shock and reduce the pressure on wages and then on non-traded goods prices.

Another feature of the Balassa-Samuelson framework is that the consumer-price differential depends only on the supply-side structure of the model. Instead in our framework, as in Rogoff (1992), a model no capital mobility and low labor mobility can also capture additional sources of

\footnotetext{
${ }^{17}$ Andres et al. (2003) acknowledge the importance of the relative price of non-traded goods but they focus on differentials that arise from price discrimination in the traded-good sector.
} 
price differentials driven by demand shocks. ${ }^{18}$ This is also the case in a more modern exposition of the Balassa-Samuelson model as in Canzoneri et al. (2001). We add also sectorial mark-up shocks to study whether changes in taxation and competition can account for consumer-price differences.

To get further insight into the model, we assume that the production functions are linear in the only factor of production, labor. In the appendix, we show that under this assumption the $\log$ of the terms of trade and the log difference of non-traded goods prices are determined by the following two equations

$$
\begin{aligned}
& \ln P_{N, t} / P_{N, t}^{*}=-\frac{\left(1-\frac{\theta}{\phi}\right)}{\left(1-\frac{b}{\phi}\right)} \hat{T}_{t}-\frac{1}{\left(1-\frac{b}{\phi}\right) \phi} \hat{G}_{t}^{R}+\frac{\left(1-\frac{1}{\phi}\right)}{\left(1-\frac{b}{\phi}\right)}\left(\hat{A}_{T, t}^{R}-\hat{A}_{N, t}^{R}\right)-\frac{1}{\left(1-\frac{b}{\phi}\right)}\left(\hat{\mu}_{T, t}^{R}-\hat{\mu}_{N, t}^{R}\right) \\
& {\left[1+\left(\eta+\frac{1}{\phi}\right) \theta \gamma-\frac{\theta}{\phi}\right] \hat{T}_{t}=}\left(\eta+\frac{1}{\phi}\right) b(1-\gamma)\left(\ln P_{N, t} / P_{N, t}^{*}\right)+\left(1-\frac{1}{\phi}\right) \hat{A}_{T}^{R} \\
&-\hat{\mu}_{T}^{R}+\left(\eta+\frac{1}{\phi}\right)\left[\gamma \hat{A}_{T}^{R}+(1-\gamma) \hat{A}_{N}^{R}\right] \\
&-\left(\eta+\frac{1}{\phi}\right)(1-\gamma) \hat{G}_{t}^{R}
\end{aligned}
$$

where the $\log$ of the terms of trade is defined as $\hat{T}_{t} \equiv \ln P_{F, t} / P_{H, t}$ and where $b \equiv \varphi \gamma+(1-\gamma) \rho^{-1}$; $\eta$-the inverse of the elasticity of labor supply- is defined as $\eta \equiv \bar{V}_{l l} \bar{L} / \bar{V}_{l}, \rho$-the risk-aversion coefficient- is given by $\rho \equiv \bar{U}_{c c} \bar{C} / \bar{U}_{c}$ and an upper index $R$ denotes the difference between the home and the foreign respective variable. First, we simplify the analysis by assuming perfect labor mobility, $\phi \rightarrow \infty$, and we combine (10) and (11) to obtain

$$
\begin{aligned}
\ln P_{N, t} / P_{N, t}^{*}= & \frac{(\theta-1) \gamma \eta}{(1+\theta \gamma \eta+\eta b(1-\gamma))} \hat{A}_{T, t}^{R}-\frac{[1+\theta \gamma \eta+\eta(1-\gamma)]}{(1+\theta \gamma \eta+\eta b(1-\gamma))} \hat{A}_{N, t}^{R}+ \\
& -\frac{\theta \gamma \eta}{(1+\theta \gamma \eta+\eta b(1-\gamma))} \hat{\mu}_{T, t}^{R}+\frac{\eta(1-\gamma)}{(1+\theta \gamma \eta+\eta b(1-\gamma))} \hat{G}_{t}^{R} \\
& +\frac{(1+\theta \gamma \eta)}{(1+\theta \gamma \eta+\eta b(1-\gamma))} \hat{\mu}_{N, t}^{R} .
\end{aligned}
$$

The above equation shows the determination of non-traded goods price differential as a function of the shocks of the economy. When the intratemporal elasticity of substitution, $\theta$, is close to one then an increase in the productivity of the home traded sector does not increase in a significant way the non-traded good price and thus the consumer price in the home economy. Contrary to the Balassa-Samuelson result, a balanced productivity shock in all the sectors within a country

\footnotetext{
${ }^{18}$ De Gregorio et al. (1994) find evidence that demand shocks can be important in explaining deviations from PPP. As well, Froot and Rogoff (1991) find that government spending can be an important explanatory variable for real exchange rate movements of several European countries in the EMS.
} 
creates a major reduction in the domestic consumer price. A relative increase in government spending in the domestic economy increases price differentials across countries. The reason is that government spending falls on non-traded goods and induces an increase in their prices. Mark-up shocks in the non-traded sector increase price differential; the opposite happens if they originate in the traded sector. A balanced mark-up shock in the domestic economy increases the price differential. In the limiting case in which domestic and foreign traded goods become perfectly substitutable (as in the Balassa-Samuelson hypothesis), i.e. $\theta$ goes to infinity, then the above solution collapses to

$$
\ln P_{N, t} / P_{N, t}^{*}=\hat{A}_{T, t}^{R}-\hat{A}_{N, t}^{R}+\hat{\mu}_{N, t}^{R}-\hat{\mu}_{T, t}^{R}
$$

which captures now the Balassa-Samuelson result augmented with mark-up shocks. Note that in this limiting case, demand shocks and balanced shocks do not matter. ${ }^{19}$ Our results on the role of the elasticity of substitution between domestic and foreign traded goods in driving the BalassaSamuelson effect are consistent with the numerical findings of Duarte and Wolman (2003).

Another illustrative case is when $\varphi=\theta=\rho=1$. Under this assumption we obtain

$$
\begin{aligned}
\ln P_{N, t} / P_{N, t}^{*}= & -\frac{(\phi \eta+1) \gamma}{(\phi-1)(1+\eta)} \hat{\mu}_{T, t}^{R}-\hat{A}_{N, t}^{R}+\frac{(1+\phi \eta)(\phi(1-\gamma)-1)-(\phi-1)}{(\phi-1) \phi(1+\eta)} \hat{G}_{t}^{R} \\
& +\frac{[\phi+(\phi \eta+1) \gamma-1]}{(\phi-1)(1+\eta)} \hat{\mu}_{N, t}^{R} .
\end{aligned}
$$

Now, the Balassa-Samuelson effect is completely muted and, most important, values of $\phi$ below one can change the sign of some of the responses as well as the magnitude.

We now go back to our more general model and calibrate it in order study which of the shocks in the model can be more relevant to explain price differential.

Table 1: Calibration of the parameters

\begin{tabular}{ll}
\hline \hline$\beta=0.99$ & Intertemporal discount factor in consumer preferences \\
$\rho=-\bar{U}_{c c} \bar{C} / \bar{U}_{c}=2$ & Risk aversion coefficient in consumer preferences \\
$\varphi=0.44$ & Elas. of substitution between traded and non-traded goods \\
$\theta=1.5$ & Elas. of substitution between domestic and foreign traded goods \\
$\sigma=7.88$ & Elas. of substitution across goods within a sector \\
$\gamma=0.5$ & Share of traded goods in the consumption bundle \\
$\eta=\bar{V}_{l l} \bar{L} / \bar{V}_{l}=0.25$ & Inverse of the Frisch elasticity of labor supply \\
$\lambda=\bar{f}^{\prime} \bar{l} / \bar{f}=0.75$ & Labor share \\
$1-\tilde{\lambda}=-\bar{f}^{\prime \prime} \bar{l} / \bar{f}^{\prime}=0.25$ & Curvature of the production function \\
\hline \hline
\end{tabular}

\footnotetext{
${ }^{19}$ As discussed in Froot and Rogoff (1995), balanced productivity shocks can matter when labor intensity differs across sectors.
} 
Table 1 presents the calibration of the parameters. The coefficient of risk aversion in consumer preferences is set to 2 as in Stockman and Tesar (1995) to get an intertemporal elasticity of substitution equal to 0.5. From Stockman and Tesar (1995), we borrow also the elasticity between traded and non-traded goods, $\varphi=0.44$, and the share of traded goods in the consumption basket, $\gamma=0.5$. The intratemporal elasticity of substitution between home and foreign traded goods is set such that $\theta=1.5$ as in Backus et al. (1995). Consistent with several microeconomic studies, the Frisch elasticity of labor supply, $1 / \eta$, is set to 4 and the labor share is set such that $\lambda=0.75$. The discount factor $\beta$ is assumed to be 0.99 and the elasticity of substitution for goods within a sector, $\sigma$, is set to 7.88 to imply a $15 \%$ mark-up as in Rotemberg and Woodford (1997). Furthermore, we assumed that in steady state the government expenditure is $20 \%$ of total output. We are not calibrating the parameter $\phi$ which measures the degree of labor mobility across sectors. Instead, we discuss three possible cases, $\phi=\infty$, which captures the perfect labor mobility case, an intermediate case of $\phi=4.5$ and a case with low elasticity, $\phi=0.5$.

With flexible prices, the real variables of the model inherit the stochastic properties of the shocks. There is no intrinsic persistence in the model. Then, Table 2 captures short- and long-run components of consumer price differentials. In particular we show the response of the consumer inflation differential and the terms of trade to a $1 \%$ increase of the shocks that are in the model. We also describe the response of terms of trade to capture the dimension through which movements in terms of trade absorb the usual Balassa-Samuelson effect. Focusing on the perfect labor mobility case, we see that a $1 \%$ increase in the traded-sector productivity in the home country does increase the price differential only of 2 basis point, consistent with the results of Duarte and Wolman (2003). The terms of trade worsen to absorb most of the shock. Instead an increase in productivity in the non-traded sector and a balanced increase in productivity in the domestic economy lower the domestic consumer price with respect to the foreign. In the same way, terms-of-trade movements absorb mark-up shocks in the traded-sector with negligible spillover on consumer prices, while mark-up shocks in the non-traded sector produce increases in prices. Government-purchase shocks that affect demand of non-traded goods increase the nontradeable goods price and thus the overall consumer price level. With intermediate values of the labor-mobility parameter, the picture does no change much. On the opposite, when $\phi$ goes below the unitary value, most of the responses are amplified and some change sign. Most important, 
the impact of government-spending shocks is of larger magnitude.

Table 2: Impulse Response

\begin{tabular}{c|cc|cc|cc}
\hline \hline & \multicolumn{2}{|c|}{$\phi \rightarrow \infty$} & \multicolumn{2}{c|}{$\phi=4.5$} & \multicolumn{2}{c}{$\phi=0.5$} \\
$1 \%$ shock to: & $\pi-\pi^{*}$ & $\frac{P_{H}}{P_{F}}$ & $\pi-\pi^{*}$ & $\frac{P_{H}}{P_{F}}$ & $\pi-\pi^{*}$ & $\frac{P_{H}}{P_{F}}$ \\
\hline$\hat{A}_{T}$ & 0.02 & 0.85 & 0.04 & 0.89 & -0.21 & 0.55 \\
$\hat{A}_{N}$ & -0.60 & 0.04 & -0.55 & 0.09 & -0.98 & -0.46 \\
$\hat{A}_{T}$ and $\hat{A}_{N}$ & -0.58 & 0.89 & -0.51 & 0.98 & -1.19 & 0.09 \\
$\hat{\mu}_{T}$ & -0.05 & -0.57 & -0.13 & -0.67 & 0.64 & 0.35 \\
$\hat{\mu}_{N}$ & 0.40 & 0.03 & 0.44 & 0.08 & 0.07 & -0.40 \\
$\hat{\mu}_{T}$ and $\hat{\mu}_{N}$ & 0.35 & -0.54 & 0.31 & -0.59 & 0.71 & -0.05 \\
$\hat{G}_{t}$ & 0.19 & -0.07 & 0.11 & -0.18 & 0.91 & 0.86 \\
\hline \hline
\end{tabular}

\section{Variance decomposition of the inflation differential}

The previous section has analyzed the extent to which various structural shocks may generate inflation differentials, which are found to be sizeable in the case of some of the shocks for a plausible parametrization of the model. We now turn to evaluating the proportion to which each of the shock contributes to the overall variability of the inflation differential implied by our model. In order to perform the variance decomposition exercise, we need to specify and calibrate the stochastic properties of all the shocks considered in the model. While a fully fledged exercise would require the estimation of all the model parameters, here we resort to a simpler analytical approach, assuming that the shocks to productivity, the mark-up and government expenditure mimic the respective ones estimated by Smets and Wouters (2003), once aggregated across sectors and countries.

Starting from the productivity shock, we assume that each one of the four productivity shocks, $\left\{A_{T, t}, A_{N, t}, A_{T, t}^{*}, A_{N, t}^{*}\right\}$, follows independent $A R(1)$ process with lag coefficient of 0.823 and standard error of the innovation of 0.012 ; this ensures that the aggregate productivity, resulting from the weighted average of the countries/sectoral ones, exactly matches the process estimated by Smets and Wouters (2003).

The shocks to government expenditure in each country are assumed to follow the same independent and very persistent $A R(1)$ process with coefficient on the lag term of 0.949 and standard deviation of the innovation of 0.0046 .

Finally, for the mark-up shocks, we impose that they are common between tradable and nontradable sectors in each economy and we also assume the same process for both economies but uncorrelated across economies. Furthermore, we impose that mark-ups are white noise processes with a standard deviation of 0.0066 , in order to match the overall variability of the price and wage mark-up shocks of Smets and Wouters (2003).

While the present calibration is admittedly ad hoc, it nonetheless provides some hints on the 
way in which different shocks contribute to the dynamic decomposition of the variance. Table 3 present the unconditional variance for several variables of the model. In particular the first column considers the CPI inflation differential. We also present the fraction of the total variance to which each shock contributes for each of the respective variables.

Table 3: Variance decomposition

\begin{tabular}{lccccccc}
\hline \hline & & $\pi-\pi^{*}$ & $\frac{P_{H}}{P_{F}}$ & $\frac{P_{N}}{P_{N}^{*}}$ & $Y-Y^{*}$ & $\frac{W}{P}$ & $\frac{W^{*}}{P *}$ \\
\hline Variance & & 0.002 & 0.021 & 0.016 & 0.033 & 0.012 & 0.012 \\
& $\hat{A}_{T}$ & 0.00 & 0.49 & 0.00 & 0.41 & 0.17 & 0.15 \\
& $\hat{A}_{N}$ & 0.44 & 0.00 & 0.49 & 0.07 & 0.63 & 0.01 \\
& $\hat{A}_{T}^{*}$ & 0.00 & 0.49 & 0.00 & 0.41 & 0.15 & 0.17 \\
Shocks & $\hat{A}_{N}^{*}$ & 0.44 & 0.00 & 0.49 & 0.07 & 0.01 & 0.63 \\
fractions of variance) & $\hat{\mu}$ & 0.06 & 0.01 & 0.01 & 0.01 & 0.03 & 0.01 \\
& $\hat{\mu}^{*}$ & 0.06 & 0.01 & 0.01 & 0.01 & 0.01 & 0.03 \\
& $\hat{G}$ & 0.00 & 0.00 & 0.00 & 0.01 & 0.00 & 0.00 \\
& $\hat{G}^{*}$ & 0.00 & 0.00 & 0.00 & 0.01 & 0.00 & 0.00 \\
\hline \hline
\end{tabular}

Focusing on the CPI inflation differential we note that the long-run variance is equal to 0.0020 which implies a standard deviation of $0.44 \%$ at quarterly frequency which roughly corresponds to a standard deviation of $0.90 \%$ yearly. ${ }^{20}$ From Table 3, productivity shocks that affect the traded sector in general do not contribute much to the variability of the inflation differential, since they are absorbed by movements in the terms of trade - indeed productivity shocks in the traded sector are responsible for most of the volatility in the terms of trade. Most important, productivity shocks in the traded sector explain the bulk of the variability of the output differential across countries.

By contrast, inflation differentials are mainly driven by productivity shocks affecting the non-tradable sector, and to a lower extent by mark-ups shocks. Productivity shocks in the non-tradable sector are also the main factor behind the variability of real wages. Interestingly, government-purchase shock do not contribute significantly to the variability of the variables displayed in the table. For government-purchase shocks, the results are in line with Duarte and Wolman (2003).

While it is not easy to draw a clear link between the results of the factor analysis in Section 2 and the variance decomposition exercise, a plausible interpretation of this evidence is to associate those underling statistical factors, identified in Section 2 for the euro area, with countries and/or sectorial productivity dynamics. However a clear investigation of those links is beyond the scope

\footnotetext{
${ }^{20}$ To convert on a yearly base, we multiplied the quarterly variance by a factor of four. This clearly understates the yearly variance because it amounts at assuming that the quarterly changes are independent over time.
} 
of this work. ${ }^{21}$

\section{Conclusions}

This paper provides both an empirical and a theoretical analysis of the factors accounting for persistent inflation differentials in a monetary union comprised of heterogenous regions. Our results indicate that asymmetric productivity shocks in the non-traded sector account for a significant fraction of the variability in the relative CPI across the two countries. Moreover, we find that symmetric sectorial productivity shocks in one country may generate sizeable inflation differentials. This stands in contrast to the conventional explanation of movements in the real exchange rate, which had pointed to movements in relative productivity in the traded sector.

This concluding Section discusses some possible avenues for future work. The model could be extended to include a third country so as to account for the component of inflation differentials that arise as a consequence of the interaction between common external shocks and the heterogeneity among euro area members in terms of their trade linkages with non-EMU partner countries. Honohan and Lane $(2003,2004)$ have emphasized the relevance of this source of inflation differentials in the euro area, showing that movements in national trade-weighted multilateral exchange rates are significantly correlated with national inflation rates. Even if our model relates to a currency area with no external trade, the previous channel of inflation differentials stemming from common external shocks could be proxied in our framework by balanced productivity shocks which interact with heterogeneous country structures.

More importantly, introducing country and sector specific degrees of nominal rigidity in price setting would permit to analyze the interaction of structural shocks, asymmetric degrees of nominal rigidities and monetary policy in shaping inflation differentials. It would also permit to assess how optimal monetary policy is affected by the presence of asymmetric degrees of nominal rigidity in sectors and countries of a monetary union. We analyze these issues in Altissimo et al. (2004).

\footnotetext{
${ }^{21}$ Such investigation is currently hampered, notably, by the limited time span of euro area data, which makes difficult to address for the moment empirical issues on long-run determinants of inflation differentials.
} 


\section{References}

[1] Alberola, E. (2000), Interpreting inflation differentials in the euro area, Banco de España Economic Bulletin, April: 61-70.

[2] Altissimo, F., P. Benigno and D. Rodriguez-Palenzuela (2004), "Inflation Differentials in a Currency Area: Facts, Explanations and Policies" mimeo, December 2004.

[3] Andrés, J., Ortega, E. and J. Vallés (2003), "Competition and Inflation Differentials in EMU," unpublished manuscript, Bank of Spain.

[4] Angeloni, I. and M. Ehrmann (2004), "Euro Area Inflation Differentials," unpublished manuscript, European Central Bank.

[5] Backus, D., P. Kehoe and F. Kydland (1995) "International Business Cycle: Theory and Evidence," in Thomas F. Cooley (ed.) Frontiers of Business Cycle Research, Princeton: Princeton University Press, pp. 331-356

[6] Backus, D. and G. W. Smith (1993), "Consumption and Real Exchange Rates in Dynamic Economies with Non-traded Goods," Journal of International Economics 35, pp. 297-316.

[7] Balassa, B., (1964), "The Purchasing Power Parity Doctrine: A Reappraisal," Journal of Political Economy, 72, pp. 584-596.

[8] Beetsma, R. and H. Jensen (2004), "Monetary and Fiscal Policy Interactions in a Microfounded Model of a Monetary Union," unpublished manuscript.

[9] Benigno, G. and C. Thoenissen (2003), "Equilibrium Exchange Rates and Supply-Side Performance," The Economic Journal, vol. 113, issue 486, pp. 103-124(1).

[10] Benigno, P. (2004), "Optimal Monetary Policy in a Currency Area," Journal of International Economics, Volume 63, Issue 2, July 2004, pp. 293-320

[11] Benigno, P. and D. Lopez-Salido (2003), "Inflation Persistence and Optimal Monetary Policy in the Euro Area," ECB working paper no. 178.

[12] Bergin, P. and R. Glick (2004), "Tradability, Productivity and Understanding International Integration," mimeo, UC-Davis and Federal Reserve Bank of San Francisco.

[13] Blanchard, O. (2001), "Country Adjustments within Euroland. Lessons after Two Years", CEPR annual report on the European Central Bank, March 2001.

[14] Burstein, A., J. Neves and S. Rebelo (2004), "Distribution Costs and Real Exchange Rate Dynamics During Exchange-Rate-Based-Stabilizations," Journal of Monetary Economics, Volume 50, Issue 6, Pages 1189-1214.

[15] Campa, J. M. and L. Goldberg (2002), "Exchange Rate Pass Through into Import Prices," unpublished manuscript.

[16] Canzoneri, M., R. Cumby, B. Diba and G. Eudey (2001), "Productivity Trends in Europe: Implications for Real Exchange Rates, Real Interest Rates and Inflation," unpublished manuscript, Georgetown University.

[17] Cecchetti, S., N. C. Mark, and R. Sonora (2002), "Price Level Convergence among United States Cities: Lessons for the European Central Bank," International Economic Review, Vol. 43, No. 4, Pages 1081-1099. 
[18] Corsetti, G, and L. Dedola (2004), "Macroeconomics of International Price Discrimination," Journal of International Economics, forthcoming.

[19] Cova, Pietro (2003), "Demand Shocks and Equilibrium Relative Prices in the Euro Area," unpublished manuscript, Georgetown university.

[20] De Grauwe, P. and F. Skudelny (2000), "Inflation and productivity differentials in EMU", mimeo, University of Leuven, May 2000.

[21] De Gregorio, J., A. Giovannini and H. Wolf (1994), "International Evidence on Tradables and Nontradables Inflation," European Economic Review 38, pp. 1225-1244.

[22] Duarte, M. (2003), "The Euro and Inflation Divergence in Europe," Federal Reserve Bank of Richmond, Economic Quarterly, Volume 89/3.

[23] Duarte, M. and A. Wolman (2002), "Regional Inflation in a Currency Union: Fiscal Policy Vs. Fundamentals," ECB Working Paper Series No. 180.

[24] Duarte, M. and A. Wolman (2003), "Fiscal Policy and Regional Inflation in a Currency Union," Federal Reserve Bank of Richmond, Working Paper No. 3-11.

[25] ECB (2003), "Inflation Differentials in the Euro Area: Potential Causes and Policy Implications".

[26] Engel, C. (1999), "Accounting for U.S. Real Exchange Rate Changes," Journal of Political Economy, vol. 107, no. 3, pp. 507-538.

[27] Engel, C. (2001), "Optimal Exchange Rate Policy: The Influence of Price Setting and Asset Markets," Journal of Money, Credit, and Banking, vol. 33, No. 2, pp. 518-541.

[28] Fitzgerald, D. (2003), "Terms-of-Trade Effects, Interdependence and Cross-Country Differences in Price Levels," unpublished manuscript, UC-Santa Cruz.

[29] Forni, M. and L. Reichlin, (2001), "Federal policies and local economies:Europe and the US," European Economic Review 45, pp. 109-134.

[30] Forni, M., M. Hallin, M. Lippi, and L. Reichlin, (2000) "The Generalized Factor Model:Identification and Estimation", The Review of Economic and Statistics, 82(4), 540554 .

[31] Froot, K. and K. Rogoff (1991), "The EMS, the EMU, and the Transition to a Common Currency", in Olivier Blanchard and Stanley Fisher (eds.) NBER Macroeconomics Annual 1991, Cambridge MA: The Mit Press.

[32] Froot, K. and K. Rogoff (1995), "Perspectives on PPP and Long-Run Real Exchange Rates," in Handbook of International Economics vol. 3, Gene Grossman and Kenneth Rogoff (eds.), (Amsterdam: Elsevier Science Publishers B.V., 1995): 1647-88.

[33] Honohan, P. and P. R. Lane (2003), "Divergent Inflation Rates under EMU," Economic Policy, 37, 358-394.

[34] Honohan, P. and P. R. Lane (2004), "Exchange Rates and Inflation under EMU: An Update," Economic Policy, Web Essay, July 2004. Available at: http://www.economicpolicy.org/responses.asp.

[35] Lombardo, G. (2004), "Inflation Targeting Rules and Welfare in an Asymmetric Currency Area," Discussion Paper, No. 04/2004, Deutsche Bundesbank. 
[36] MacDonald R. and L. Ricci (2002), "Purchasing Power Parity and New Trade Theory," IMF working paper 02-32.

[37] Mendoza, E. (2000), "On the Instability of Variance Decompositions of the Real Exchange Rate Across Exchange-Rate-Regimes: Evidence from Mexico and the United States," NBER Working Paper 7768.

[38] Obstfeld, M., Rogoff, K. (2000), "New Directions for Stochastic Open Economy Models," Journal of International Economics 50, 117-153.

[39] Ortega, E. (2003), "Persistent Inflation Differentials in Europe," Banco De Espana, Economic Bulletin, January 2003.

[40] Rogoff, K. (1996), "The Purchasing Power Parity Puzzle," Journal of Economic Literature Vol. XXXIV, pp. 647-668.

[41] Rotemberg, J.J., Woodford, M., 1997. An optimization-based econometric framework for the evaluation of monetary policy, in Bernanke, B.S., Rotemberg, J.J, (Eds.), NBER Macroeconomic Annual 1997, MIT Press, Cambridge, pp. 297-346.

[42] Samuelson, P. A., (1964), "Theoretical Notes on Trade Problems," Review of Economics and Statistics 46, pp. 145-164.

[43] Smets, F. and R. Wouters (2004), "An Estimated Stochastic Dynamic General Equilibrium Model of the Euro Area," Journal of the European Economic Association vol. 1, Issue 5, pp. $1123-1175$.

[44] Sondergaard, L. (2003), "Inflation Dynamics in the Traded Sectors of France, Italy and Spain," unpublished manuscript, Georgetown University.

[45] Stockman, A. and L. Tesar, (1994), "Tastes in a Two-Country Model of the Business Cycle: Explaining International Comovement," American Economic Review, vol. 85 No. 1, pp. 168185.

[46] Stock, J. and M. Watson, (1999), "Diffusion Index ", NBER working paper 6702.

[47] Woodford, M. (2003), Interest and Prices: Foundations of a Theory of Monetary Policy, Princeton University Press. 


\section{Appendix: model solution}

We remind that in the traded sector of country $H$, the first-order conditions for price-setting behavior imply

$$
1=\mu_{T, t} \frac{P_{t}}{P_{T, t}} \frac{P_{T, t}}{P_{H, t}} \frac{V_{l}\left(L_{t}\right)}{U_{c}\left(C_{t}\right)}\left(\frac{l_{T, t}}{L_{t}}\right)^{-\frac{1}{\phi}} \frac{1}{f^{\prime}\left(l_{T, t}\right) A_{T, t}} ;
$$

in the traded sector of country $F$, we obtain that

$$
1=\mu_{T, t}^{*} \frac{P_{t}^{*}}{P_{T, t}^{*}} \frac{P_{T, t}^{*}}{P_{F, t}} \frac{V_{l}\left(L_{t}^{*}\right)}{U_{c}\left(C_{t}^{*}\right)}\left(\frac{l_{T, t}^{*}}{L_{t}^{*}}\right)^{-\frac{1}{\phi}} \frac{1}{f^{\prime}\left(l_{T, t}^{*}\right) A_{T, t}} .
$$

In the non-traded sectors, respectively in country $H$ and $F$, we obtain that

$$
\begin{aligned}
& 1=\mu_{N, t} \frac{P_{t}}{P_{N, t}} \frac{V_{l}\left(L_{t}\right)}{U_{c}\left(C_{t}\right)}\left(\frac{l_{N, t}}{L_{t}}\right)^{-\frac{1}{\phi}} \frac{1}{f^{\prime}\left(l_{N, t}\right) A_{N, t}}, \\
& 1=\mu_{N, t}^{*} \frac{P_{t}^{*}}{P_{N, t}^{*}} \frac{V_{l}\left(L_{t}^{*}\right)}{U_{c}\left(C_{t}^{*}\right)}\left(\frac{l_{N, t}^{*}}{L_{t}^{*}}\right)^{-\frac{1}{\phi}} \frac{1}{f^{\prime}\left(l_{N, t}^{*}\right) A_{N, t}^{*}} .
\end{aligned}
$$

We define $T \equiv P_{F} / P_{H}, T_{N} \equiv P_{N} / P_{T}$ and $T_{N}^{*} \equiv P_{N}^{*} / P_{T}^{*}$. Note that since the law of one price holds for traded goods it follows that $P_{F}=P_{F}^{*}$ and $P_{H}=P_{H}^{*}$. Using the definition of the price indexes, we obtain that

$$
\begin{array}{ll}
\left(\frac{P_{H, t}}{P_{T, t}}\right)^{\theta-1}=n+(1-n) T_{t}^{1-\theta}, & \left(\frac{P_{H, t}}{P_{T, t}^{*}}\right)^{\theta-1}=n^{*}+\left(1-n^{*}\right) T_{t}^{1-\theta} \\
\left(\frac{P_{F, t}}{P_{T, t}}\right)^{\theta-1}=n T_{t}^{\theta-1}+(1-n), & \left(\frac{P_{F, t}}{P_{T, t}^{*}}\right)^{\theta-1}=n^{*} T_{t}^{\theta-1}+\left(1-n^{*}\right), \\
\left(\frac{P_{N, t}}{P_{t}}\right)^{\varphi-1}=\omega T_{N, t}^{\varphi-1}+(1-\omega), & \left(\frac{P_{N, t}^{*}}{P_{t}^{*}}\right)^{\varphi-1}=\omega^{*} T_{N, t}^{* \varphi-1}+\left(1-\omega^{*}\right), \\
\left(\frac{P_{T, t}}{P_{t}}\right)^{\varphi-1}=\omega+(1-\omega) T_{N, t}^{1-\varphi}, & \left(\frac{P_{T, t}^{*}}{P_{t}^{*}}\right)^{\varphi-1}=\omega^{*}+\left(1-\omega^{*}\right) T_{N, t}^{* 1-\varphi} .
\end{array}
$$

We finally note that (19) imply

$$
\frac{P_{t}}{P_{t}^{*}}=\frac{P_{T, t}}{P_{T, t}^{*}} \frac{\left[\omega+(1-\omega) T_{N, t}^{1-\varphi}\right]^{\frac{1}{1-\varphi}}}{\left[\omega^{*}+\left(1-\omega^{*}\right) T_{N, t}^{* 1-\varphi}\right]^{\frac{1}{1-\varphi}}}
$$

moreover (16) imply

$$
\frac{P_{T, t}}{P_{T, t}^{*}}=\frac{\left[n+(1-n) T_{t}^{1-\theta}\right]^{\frac{1}{1-\theta}}}{\left[n^{*}+\left(1-n^{*}\right) T_{t}^{1-\theta}\right]^{\frac{1}{1-\theta}}}
$$


We can finally write that

$$
\frac{P_{t}}{P_{t}^{*}}=\frac{\left[n+(1-n) T_{t}^{1-\theta}\right]^{\frac{1}{1-\theta}}}{\left[n^{*}+\left(1-n^{*}\right) T_{t}^{1-\theta}\right]^{\frac{1}{1-\theta}}} \frac{\left[\omega+(1-\omega) T_{N, t}^{1-\varphi}\right]^{\frac{1}{1-\varphi}}}{\left[\omega^{*}+\left(1-\omega^{*}\right) T_{N, t}^{* 1-\varphi}\right]^{\frac{1}{1-\varphi}}}
$$

which can be substituted in (7) to obtain

$$
\frac{U_{C}\left(C_{t}\right)}{U_{C}\left(C_{t}^{*}\right)}=\frac{\left[n+(1-n) T_{t}^{1-\theta}\right]^{\frac{1}{1-\theta}}}{\left[n^{*}+\left(1-n^{*}\right) T_{t}^{1-\theta}\right]^{\frac{1}{1-\theta}}} \frac{\left[\omega+(1-\omega) T_{N, t}^{1-\varphi}\right]^{\frac{1}{1-\varphi}}}{\left[\omega^{*}+\left(1-\omega^{*}\right) T_{N, t}^{* 1-\varphi}\right]^{\frac{1}{1-\varphi}}} .
$$

We note that $L_{T, t}=\gamma l_{T, t}$ and $L_{T, t}^{*}=\gamma^{*} l_{T, t}^{*}$ and $L_{N, t}=(1-\gamma) l_{N, t}$ and $L_{N, t}^{*}=\left(1-\gamma^{*}\right) l_{N, t}^{*}$ so that

$$
\begin{aligned}
& L_{t}=\left[\gamma\left(l_{T, t}\right)^{\frac{\phi-1}{\phi}}+(1-\gamma)\left(l_{N, t}\right)^{\frac{\phi-1}{\phi}}\right]^{\frac{\phi}{\phi-1}} \\
& L_{t}^{*}=\left[\gamma\left(l_{T, t}^{*}\right)^{\frac{\phi-1}{\phi}}+(1-\gamma)\left(l_{N, t}^{*}\right)^{\frac{\phi-1}{\phi}}\right]^{\frac{\phi}{\phi-1}}
\end{aligned}
$$

The sectorial demand of goods are given by

$$
\begin{gathered}
y_{T, t}=\frac{n \omega}{\gamma}\left(\frac{P_{H}}{P_{T}}\right)^{-\theta}\left(\frac{P_{T}}{P}\right)^{-\varphi} C+\frac{n^{*} \omega^{*}}{\gamma}\left(\frac{P_{H}}{P_{T}^{*}}\right)^{-\theta}\left(\frac{P_{T}^{*}}{P^{*}}\right)^{-\varphi} C^{*} \\
y_{T, t}^{*}=\frac{(1-n) \omega}{\gamma^{*}}\left(\frac{P_{F}}{P_{T}}\right)^{-\theta}\left(\frac{P_{T}}{P}\right)^{-\varphi} C+\frac{\left(1-n^{*}\right) \omega^{*}}{\gamma^{*}}\left(\frac{P_{F}}{P_{T}^{*}}\right)^{-\theta}\left(\frac{P_{T}^{*}}{P^{*}}\right)^{-\varphi} C^{*} \\
y_{N, t}=\frac{1-\omega}{1-\gamma}\left(\frac{P_{N, t}}{P_{t}}\right)^{-\varphi} C_{t}+G_{t} \\
y_{N, t}^{*}=\frac{1-\omega^{*}}{1-\gamma^{*}}\left(\frac{P_{N, t}^{*}}{P_{t}^{*}}\right)^{-\varphi} C_{t}^{*}+G_{t}^{*} .
\end{gathered}
$$

while

$$
\begin{aligned}
& l_{T, t}=f^{-1}\left(\frac{y_{T, t}}{A_{T, t}}\right), \\
& l_{T, t}^{*}=f^{-1}\left(\frac{y_{T, t}^{*}}{A_{T, t}^{*}}\right) \\
& l_{N, t}=f^{-1}\left(\frac{y_{N, t}}{A_{N, t}}\right), \\
& l_{N, t}^{*}=f^{-1}\left(\frac{y_{N, t}^{*}}{A_{N, t}^{*}}\right)
\end{aligned}
$$

Equations from (12) to (31) should be solved for the variables $\left\{\frac{P_{t}}{P_{T, t}}, \frac{P_{T, t}}{P_{H, t}}, L_{t}, C_{t}, l_{T, t}, \frac{P_{t}^{*}}{P_{T, t}^{*}}, \frac{P_{T, t}^{*}}{P_{F, t}}\right.$, $\left.L_{t}^{*}, C_{t}^{*}, l_{T, t}^{*}, \frac{P_{t}}{P_{N, t}}, \frac{P_{t}^{*}}{P_{N, t}^{*}}, l_{N, t}^{*}, l_{N, t}, T_{t}, T_{N, t}, T_{N, t}^{*}, \frac{P_{F, t}}{P_{T, t}}, \frac{P_{F, t}}{P_{T, t}^{*}}, y_{T, t}, y_{T, t}^{*}, y_{N, t}, y_{N, t}^{*}\right\}$ given the processes $\left\{\mu_{T, t}, \mu_{T, t}^{*}, \mu_{N, t}, \mu_{N, t}^{*}, A_{T, t}, A_{T, t}^{*}, A_{N, t}, A_{N, t}^{*}, G_{t}, G_{t}^{*}\right\}$. 
We approximate the previous solution around a deterministic steady state in which the process $\left\{\mu_{T, t}, \mu_{T, t}^{*}, \mu_{N, t}, \mu_{N, t}^{*}, A_{T, t}, A_{T, t}^{*}, A_{N, t}, A_{N, t}^{*}, G_{t}, G_{t}^{*}\right\}$ are such that $\bar{\mu}_{H}=\bar{\mu}_{H}^{*}=\bar{\mu}_{F}=\bar{\mu}_{F}^{*}=$ $\bar{\mu}_{N}=\bar{\mu}_{N}^{*}=\bar{\mu}$ and $\bar{A}_{T}=\bar{A}_{T}^{*}=\bar{A}_{N}=\bar{A}_{N}^{*}=\bar{A}, \bar{G}=\bar{G}^{*}=0 .{ }^{22}$ We assume for simplicity that $\gamma=\gamma^{*}, n=n^{*}=1 / 2, \omega=\omega^{*}=\gamma$. We show that there is a steady-state in which $\frac{P_{t}}{P_{T, t}}=\frac{P_{T, t}}{P_{H, t}}=\frac{P_{t}^{*}}{P_{T, t}^{*}}=\frac{P_{T, t}^{*}}{P_{F, t}}=\frac{P_{t}}{P_{N, t}}=\frac{P_{t}^{*}}{P_{N, t}^{*}}=\frac{P_{F, t}}{P_{T, t}}=\frac{P_{F, t}}{P_{T, t}^{*}}=T_{t}=T_{N, t}=T_{N, t}^{*}=1, L_{t}=$ $l_{T, t}=l_{N, t}=\bar{L}$ and $L_{t}^{*}=l_{T, t}^{*}=l_{N, t}^{*}=\bar{L}^{*}, y_{T, t}=y_{T, t}^{*}=y_{N, t}=y_{N, t}^{*}=C_{t}=C_{t}^{*}=\bar{C}$. It is clear that equations (16-27) are satisfied by the above steady-state conditions. Moreover (28), (29), (30), (31) imply that

$$
\bar{L}=f^{-1}\left(\frac{\bar{C}}{\bar{A}}\right)=\bar{L}^{*}
$$

while (12), (13), (14), (15) imply

$$
1=\bar{\mu} \frac{V_{l}(\bar{L})}{U_{c}(\bar{C})} \frac{1}{f^{\prime}(\bar{L}) \bar{A}} .
$$

Equations (32) and (33) can be solved for $\bar{L}$ and $\bar{C}$ given $\bar{A}$. Under standard preference specifications the values $\bar{L}$ and $\bar{C}$ exist uniquely.

Maintaining the assumption that $\gamma=\gamma^{*}, n=n^{*}=1 / 2, \omega=\omega^{*}=\gamma$ we study the solution of the model in a log-linear approximation of the structural equations for small perturbations of the exogenous shocks around the steady state outlined above. We start by log-linearizing equations (16) to (19). We obtain that

$$
\begin{gathered}
\widehat{\frac{P_{H, t}}{P_{T, t}}}=\frac{\widehat{P_{H, t}}}{P_{T, t}^{*}}=-\frac{1}{2} \hat{T}_{t}=-\frac{\widehat{P_{F, t}}}{P_{T, t}^{*}}=-\frac{\widehat{P_{F, t}}}{P_{T, t}} \\
\frac{\widehat{P_{N, t}}}{P_{t}}=\gamma \hat{T}_{N, t}=-\frac{\gamma}{1-\gamma} \frac{\widehat{P_{T, t}}}{P_{t}} \\
\frac{\widehat{P_{N, t}^{*}}}{P_{t}^{*}}=\gamma \hat{T}_{N, t}^{*}=-\frac{\gamma}{1-\gamma} \frac{\widehat{P_{T, t}^{*}}}{P_{t}^{*}}
\end{gathered}
$$

Equation (21) yields to

$$
-\rho\left(\hat{C}_{t}-\hat{C}_{t}^{*}\right)=(1-\gamma)\left(\hat{T}_{N, t}-\hat{T}_{N, t}^{*}\right) .
$$

A log-linear approximation to (12), (13), (14), (15) yields to

$$
\begin{gathered}
\hat{\mu}_{T, t}+(1-\gamma) \hat{T}_{N, t}+\frac{1}{2} \hat{T}_{t}+\eta \hat{L}_{t}+\rho \hat{C}_{t}-\frac{1}{\phi}\left(\hat{l}_{T, t}-\hat{L}_{t}\right)-\hat{A}_{T, t}+(1-\tilde{\lambda}) \hat{l}_{T, t}=0 \\
\hat{\mu}_{T, t}^{*}+(1-\gamma) \hat{T}_{N, t}^{*}-\frac{1}{2} \hat{T}_{t}^{*}+\eta \hat{L}_{t}^{*}+\rho \hat{C}_{t}^{*}-\frac{1}{\phi}\left(\hat{l}_{T, t}^{*}-\hat{L}_{t}^{*}\right)-\hat{A}_{T, t}^{*}+(1-\tilde{\lambda}) \hat{l}_{T, t}^{*}=0 \\
\hat{\mu}_{N, t}-\gamma \hat{T}_{N, t}+\eta \hat{L}_{t}+\rho \hat{C}_{t}-\frac{1}{\phi}\left(\hat{l}_{N, t}-\hat{L}_{t}\right)-\hat{A}_{N, t}+(1-\tilde{\lambda}) \hat{l}_{N, t}=0 \\
\hat{\mu}_{N, t}^{*}-\gamma \hat{T}_{N, t}^{*}+\eta \hat{L}_{t}^{*}+\rho \hat{C}_{t}^{*}-\frac{1}{\phi}\left(\hat{l}_{N, t}^{*}-\hat{L}_{t}^{*}\right)-\hat{A}_{N, t}^{*}+(1-\tilde{\lambda}) \hat{l}_{N, t}^{*}=0
\end{gathered}
$$

\footnotetext{
${ }^{22}$ In the numerical solution of sections 4 and 5 of the text, we instead assume a positive share of government consumption over output in the steady state.
} 
where $\eta \equiv \bar{V}_{l l} \bar{l} / \bar{V}_{l}, \rho \equiv-\bar{U}_{c c} \bar{C} / \bar{U}_{c},(1-\tilde{\lambda}) \equiv-\bar{f}^{\prime \prime} \bar{l} / \bar{f}^{\prime}$ with $\tilde{\lambda} \leq 1$. A log-linear approximation to equations (22) and (23) yields to

$$
\begin{aligned}
& \hat{L}_{t}=\gamma \hat{l}_{T, t}+(1-\gamma) \hat{l}_{N, t}, \\
& \hat{L}_{t}^{*}=\gamma \hat{l}_{T, t}^{*}+(1-\gamma) \hat{l}_{N, t}^{*} .
\end{aligned}
$$

A log-linear approximation to equations (24), (25), (26), (27) yields

$$
\begin{gathered}
\hat{y}_{T, t}=\frac{\theta}{2} \hat{T}_{t}+\frac{\varphi}{2}(1-\gamma) \hat{T}_{N, t}+\frac{1}{2} \hat{C}_{t}+\frac{\varphi}{2}(1-\gamma) \hat{T}_{N, t}^{*}+\frac{1}{2} \hat{C}_{t}^{*}, \\
\hat{y}_{T, t}^{*}=-\frac{\theta}{2} \hat{T}_{t}+\frac{\varphi}{2}(1-\gamma) \hat{T}_{N, t}+\frac{1}{2} \hat{C}_{t}+\frac{\varphi}{2}(1-\gamma) \hat{T}_{N, t}^{*}+\frac{1}{2} \hat{C}_{t}^{*}, \\
\hat{y}_{N, t}=-\varphi \gamma \hat{T}_{N, t}+\hat{C}_{t}+\hat{G}_{t}, \\
\hat{y}_{N, t}^{*}=-\varphi \gamma \hat{T}_{N, t}^{*}+\hat{C}_{t}^{*}+\hat{G}_{t}^{*},
\end{gathered}
$$

where $\hat{G}_{t}=G_{t} / \bar{Y}$ and $\hat{G}_{t}^{*}=G_{t}^{*} / \bar{Y}$. Finally a log-linear approximation to (28), (29), (30), (31) imply

$$
\begin{aligned}
\lambda \hat{l}_{T, t} & =\hat{y}_{T, t}-\hat{A}_{T, t} \\
\lambda \hat{l}_{T, t}^{*} & =\hat{y}_{T, t}^{*}-\hat{A}_{T, t}^{*} \\
\lambda \hat{l}_{N, t} & =\hat{y}_{N, t}-\hat{A}_{N, t} \\
\lambda \hat{l}_{N, t}^{*} & =\hat{y}_{N, t}^{*}-\hat{A}_{N, t}^{*}
\end{aligned}
$$

where $\lambda \equiv \bar{f}^{\prime} \bar{l} / \bar{f}$. with $0<\lambda \leq 1$.

We first solve the model for the aggregate variables and then we solve for relative prices and consumption. First, we take a weighted average of equations (35) and (37) with weights $\gamma$ and $1-\gamma$ and obtain

$$
\gamma \hat{\mu}_{T, t}+(1-\gamma) \hat{\mu}_{N, t}+\frac{\gamma}{2} \hat{T}_{t}+(\eta+1-\tilde{\lambda}) \hat{L}_{t}+\rho \hat{C}_{t}-\gamma \hat{A}_{T, t}-(1-\gamma) \hat{A}_{N, t}=0
$$

and take a weighted average of equations (36) and (38) to obtain

$$
\gamma \hat{\mu}_{T, t}^{*}+(1-\gamma) \hat{\mu}_{N, t}^{*}-\frac{\gamma}{2} \hat{T}_{t}+(\eta+1-\tilde{\lambda}) \hat{L}_{t}^{*}+\rho \hat{C}_{t}^{*}-\gamma \hat{A}_{T, t}^{*}-(1-\gamma) \hat{A}_{N, t}^{*}=0
$$

We can define $\hat{\mu}_{t} \equiv \gamma \hat{\mu}_{T, t}+(1-\gamma) \hat{\mu}_{N, t}, \hat{\mu}_{t}^{*} \equiv \gamma \hat{\mu}_{T, t}^{*}+(1-\gamma) \hat{\mu}_{N, t}^{*}, \hat{A}_{t} \equiv \gamma \hat{A}_{T, t}+(1-\gamma) \hat{A}_{N, t}$, $\hat{A}_{t}^{*} \equiv \gamma \hat{A}_{T, t}^{*}+(1-\gamma) \hat{A}_{N, t}^{*}$ and take a weighted average of the above conditions with weights $1 / 2$ and obtain

$$
\hat{\mu}_{t}^{W}+(\eta+1-\tilde{\lambda}) \hat{L}_{t}^{W}+\rho \hat{C}_{t}^{W}-\hat{A}_{t}^{W}=0
$$

where an index $W$ denotes a weighted average of home and foreign variables. We can as well take a weighted average of (41) to (44), with weights $\frac{\gamma}{2}, \frac{\gamma}{2}, \frac{1-\gamma}{2}, \frac{1-\gamma}{2}$

$$
\frac{\gamma}{2} \hat{y}_{T, t}+\frac{\gamma}{2} \hat{y}_{T, t}^{*}+\frac{(1-\gamma)}{2} \hat{y}_{N, t}^{*}+\frac{(1-\gamma)}{2} \hat{y}_{N, t}=\hat{C}_{t}^{W}+(1-\gamma) \hat{G}_{t}^{W} .
$$


We can use (45) to (48) to obtain

$$
\hat{C}_{t}^{W}+(1-\gamma) \hat{G}_{t}^{W}=\lambda \hat{L}_{t}^{W}+\hat{A}_{t}^{W} .
$$

We can use (49) and (50) to obtain

$$
\hat{L}_{t}^{W}=\frac{1-\rho}{\lambda(\tilde{\eta}+\rho)} \hat{A}_{t}^{W}+\frac{\rho(1-\gamma)}{\lambda(\tilde{\eta}+\rho)} \hat{G}_{t}^{W}-\frac{1}{\lambda(\tilde{\eta}+\rho)} \hat{\mu}_{t}^{W}
$$

and

$$
\begin{aligned}
\hat{C}_{t}^{W} & =\frac{\tilde{\eta}+1}{(\tilde{\eta}+\rho)} \hat{A}_{t}^{W}-\frac{\tilde{\eta}(1-\gamma)}{(\tilde{\eta}+\rho)} \hat{G}_{t}^{W}-\frac{1}{(\tilde{\eta}+\rho)} \hat{\mu}_{t}^{W} \\
\hat{Y}_{t}^{W} & =\frac{\tilde{\eta}+1}{(\tilde{\eta}+\rho)} \hat{A}_{t}^{W}+\frac{\rho(1-\gamma)}{(\tilde{\eta}+\rho)} \hat{G}_{t}^{W}-\frac{1}{(\tilde{\eta}+\rho)} \hat{\mu}_{t}^{W}
\end{aligned}
$$

where we have defined $\tilde{\eta} \equiv(1-\tilde{\lambda}+\eta) / \lambda$. To solve for the difference variables in the model, we first consider equation (34) which can be written as

$$
-\rho \hat{C}_{t}^{R}=(1-\gamma) \hat{T}_{N, t}^{R}
$$

where a variable with a superscript $R$ has been defined as the difference between the respective home and foreign variable.

We can take the difference between equations (35) and (36) to obtain

$$
\hat{\mu}_{T, t}^{R}+(1-\gamma) \hat{T}_{N, t}^{R}+\hat{T}_{t}+c_{1}(1-\gamma) \hat{l}_{N, t}^{R}+\rho \hat{C}_{t}^{R}+\left(\gamma c_{1}+c_{2}\right) \hat{l}_{T, t}^{R}-\hat{A}_{T, t}^{R}=0
$$

where we have defined $c_{1} \equiv\left(\eta+\frac{1}{\phi}\right)$ and $c_{2} \equiv(1-\tilde{\lambda})-\frac{1}{\phi}$. Using (51) we can obtain

$$
\hat{\mu}_{T, t}^{R}+\hat{T}_{t}+c_{1}(1-\gamma) \hat{l}_{N, t}^{R}+\left(\gamma c_{1}+c_{2}\right) \hat{l}_{T, t}^{R}-\hat{A}_{T, t}^{R}=0 .
$$

We can take the difference between (37) and (38) to obtain

$$
\hat{\mu}_{N, t}^{R}-\gamma \hat{T}_{N, t}^{R}+\gamma c_{1} \hat{l}_{T, t}^{R}+\rho \hat{C}_{t}^{R}-\hat{A}_{N, t}^{R}+\left[(1-\gamma) c_{1}+c_{2}\right] \hat{l}_{N, t}=0,
$$

which can be written as

$$
\hat{\mu}_{N, t}^{R}-\hat{T}_{N, t}^{R}+\gamma c_{1} \hat{l}_{T, t}^{R}-\hat{A}_{N, t}^{R}+\left[(1-\gamma) c_{1}+c_{2}\right] \hat{l}_{N, t}=0,
$$

We can use equations (52) and (53) to solve for $\hat{l}_{T, t}^{R}$ to obtain

$$
\lambda \tilde{\eta} c_{3} \hat{l}_{T, t}^{R}=-c_{4} \hat{\mu}_{T, t}^{R}-c_{4} \hat{T}_{t}+c_{4} \hat{A}_{T, t}^{R}+c_{1}(1-\gamma) \hat{\mu}_{N, t}^{R}-c_{1}(1-\gamma) \hat{T}_{N, t}^{R}-c_{1}(1-\gamma) \hat{A}_{N, t}^{R}
$$

where $c_{3} \equiv(1-\tilde{\lambda})-\frac{1}{\phi}$ and $c_{4} \equiv(1-\gamma) c_{1}+c_{2}$.

We can also use (52) and (53) to solve for $\hat{l}_{N, t}^{R}$ to obtain

$$
\lambda \tilde{\eta} \xi_{\phi} \hat{l}_{N, t}^{R}=\gamma c_{1} \hat{\mu}_{T, t}^{R}+\gamma c_{1} \hat{T}_{t}-\gamma c_{1} \hat{A}_{T, t}^{R}-c_{5} \hat{\mu}_{N, t}^{R}+c_{5} \hat{T}_{N, t}^{R}+c_{5} \hat{A}_{N, t}^{R}
$$

where $c_{5} \equiv \gamma c_{1}+c_{2}$. 
We can take the difference between (43) and (44), after using (47), (48) and 51 to obtain

$$
\hat{l}_{N, t}^{R}=-c_{6} \hat{T}_{N, t}^{R}+\frac{1}{\lambda} \hat{G}_{t}^{R}-\frac{1}{\lambda} \hat{A}_{N, t}^{R}
$$

where $c_{6}=\varphi \gamma / \lambda+(1-\gamma) /(\rho \lambda)$. We can now take the difference between (41) and (42) and use the difference between (45) and (46) to obtain

$$
\hat{l}_{T, t}^{R}=\frac{\theta}{\lambda} \hat{T}_{t}-\frac{1}{\lambda} \hat{A}_{T, t}^{R}
$$

Equations (54), (55), (56), (57) can be solved for $\hat{l}_{N, t}^{R}, \hat{l}_{T, t}^{R}, \hat{T}_{N, t}^{R}, \hat{T}_{t}$. We can write the following matrix form in relation to the vector $x_{t}=\left[\begin{array}{llll}\hat{l}_{T, t}^{R} & \hat{l}_{N, t}^{R} & \hat{T}_{t} & \hat{T}_{N, t}^{R}\end{array}\right]$

$$
A x_{t}=B s_{t}
$$

where $s_{t}=\left[\begin{array}{lll}\hat{\mu}_{T, t}^{R} & \hat{\mu}_{N, t}^{R} \hat{A}_{T, t}^{R} \hat{A}_{N, t}^{R} \hat{G}_{t}^{R}\end{array}\right]$

$$
\begin{gathered}
A=\left[\begin{array}{cccc}
\lambda \tilde{\eta} c_{3} & 0 & c_{4} & c_{1}(1-\gamma) \\
0 & \lambda \tilde{\eta} c_{3} & -\gamma c_{1} & -c_{5} \\
1 & 0 & -\frac{\theta}{\lambda} & 0 \\
0 & 1 & 0 & c_{6}
\end{array}\right] \\
B=\left[\begin{array}{ccccc}
-c_{4} & c_{1}(1-\gamma) & c_{4} & -c_{1}(1-\gamma) & 0 \\
\gamma c_{1} & -c_{5} & -\gamma c_{1} & c_{5} & 0 \\
0 & 0 & -\frac{1}{\lambda} & 0 & 0 \\
0 & 0 & 0 & -\frac{1}{\lambda} & \frac{1}{\lambda}
\end{array}\right]
\end{gathered}
$$

We can obtain the solution of the model for the flexible price allocations as

$$
x_{t}=A^{-1} B s_{t} .
$$

\subsection{Special case of linear production function reported in the text}

In the linear case, i.e. $\lambda=1$ and $\tilde{\lambda}=1$, the relevant equations for the determination of $\left(\hat{T}_{t}, \hat{T}_{N, t}^{R}, \hat{L}_{t}^{R}, \hat{l}_{T, t}^{R}, \hat{l}_{N, t}^{R}\right)$ reduced to

$$
\begin{gathered}
\hat{\mu}_{T, t}^{R}+\hat{T}_{t}+\eta \hat{L}_{t}^{R}-\frac{1}{\phi}\left(\hat{l}_{T, t}^{R}-\hat{L}_{t}^{R}\right)-\hat{A}_{T, t}^{R}=0 \\
\hat{\mu}_{N, t}^{R}-\hat{T}_{N, t}^{R}+\eta \hat{L}_{t}^{R}-\frac{1}{\phi}\left(\hat{l}_{N, t}^{R}-\hat{L}_{t}^{R}\right)-\hat{A}_{N, t}^{R}=0 \\
\hat{l}_{N, t}^{R}=-b \hat{T}_{N, t}^{R}+\hat{G}_{t}^{R}-\hat{A}_{N, t}^{R} \\
\hat{l}_{T, t}^{R}=\theta \hat{T}_{t}-\hat{A}_{T, t}^{R} \\
\hat{L}_{t}^{R}=\gamma \hat{l}_{T, t}^{R}+(1-\gamma) \hat{l}_{N, t}^{R}
\end{gathered}
$$

where $b \equiv \varphi \gamma+(1-\gamma) \rho^{-1}$. Simple algebraic manipulation shows how to solve for $\left(\hat{T}_{N, t}^{R}, \hat{T}_{t}\right)$ and obtain equations (10) and (11) in the text. 


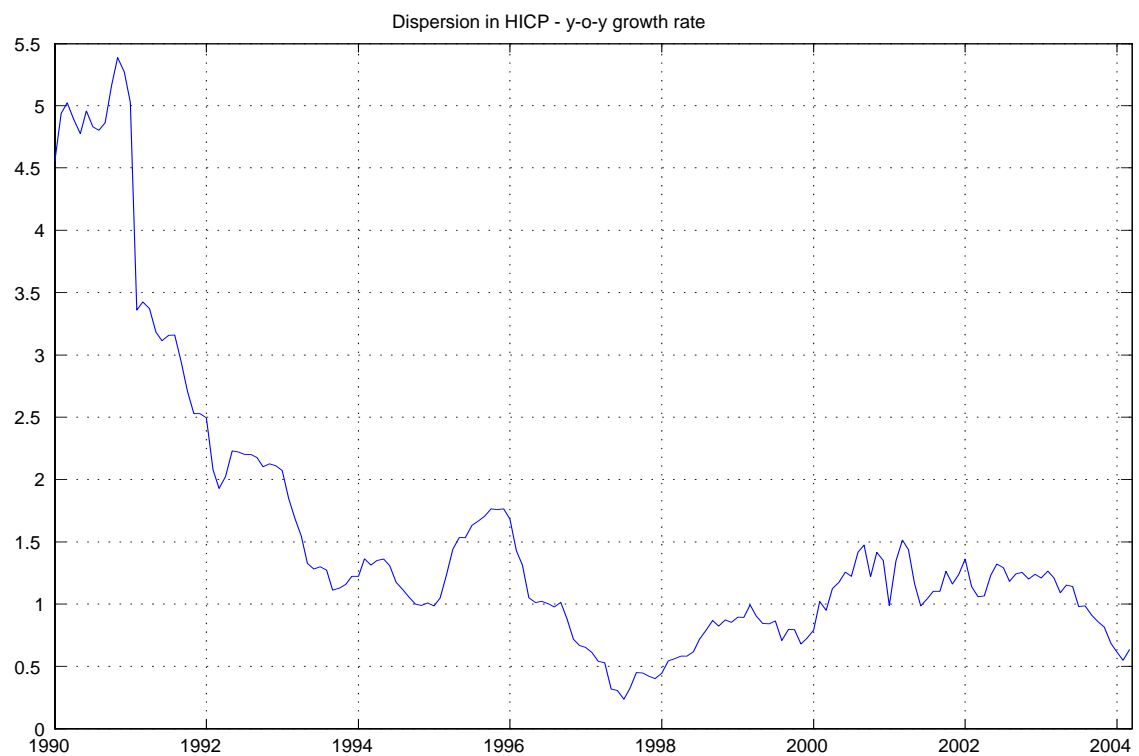

Fig. 1: Dispersion in HICP - y-o-y growth rate
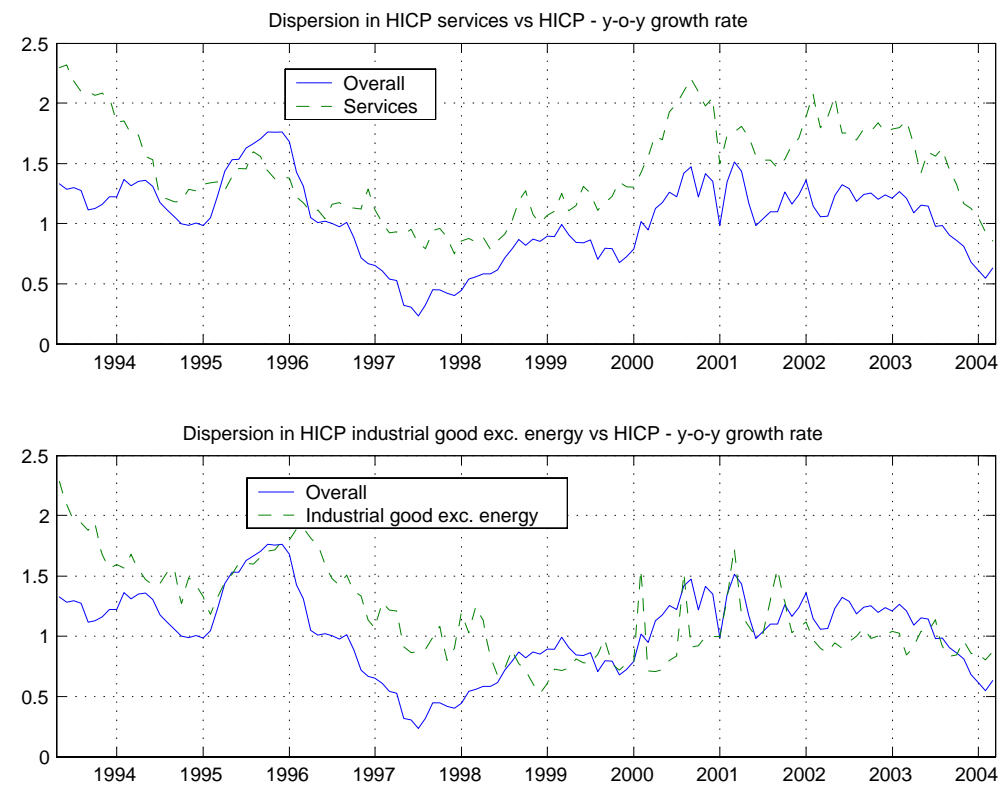

Fig. 2-a: Dispersion by sector. 

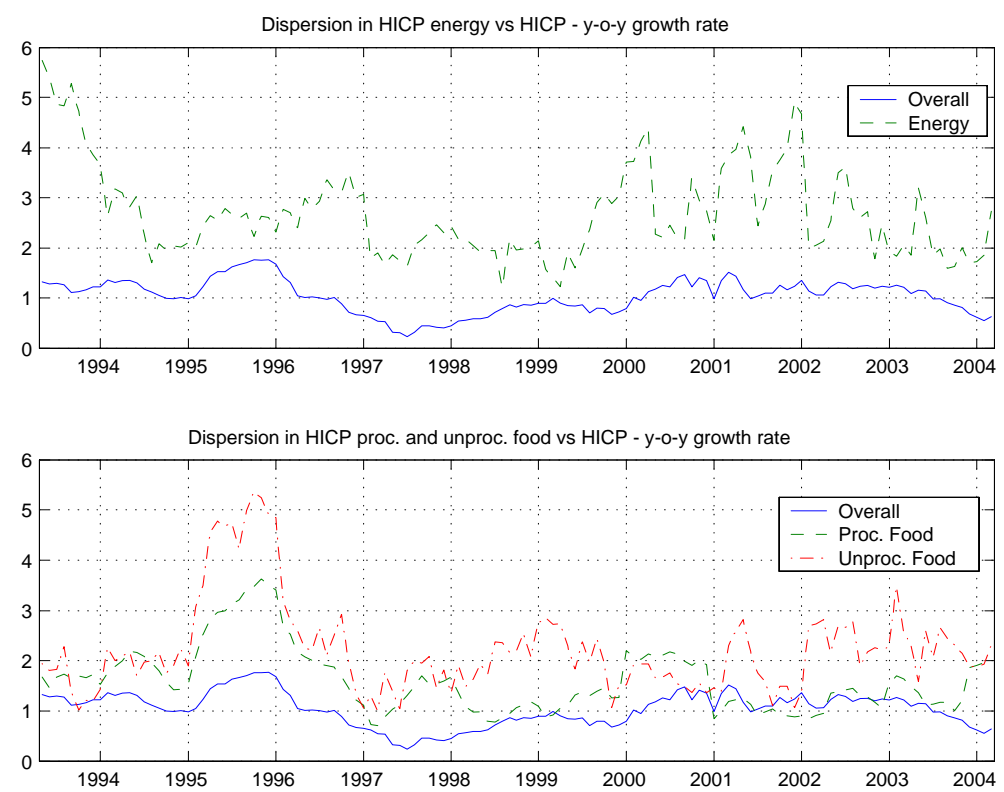

Fig. 2-b: Dispersion by sector.
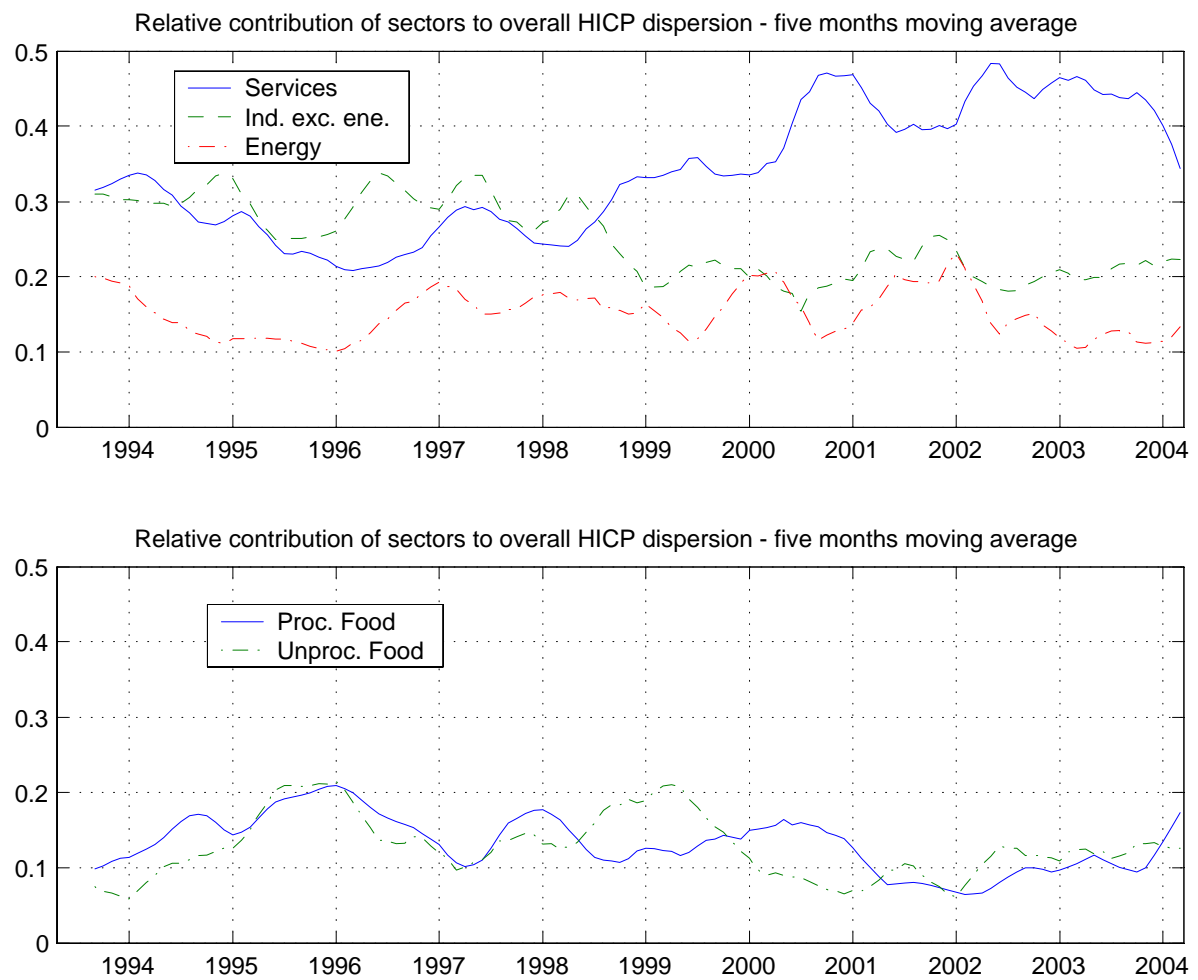

Fig. 3: Dispersion decomposition. 


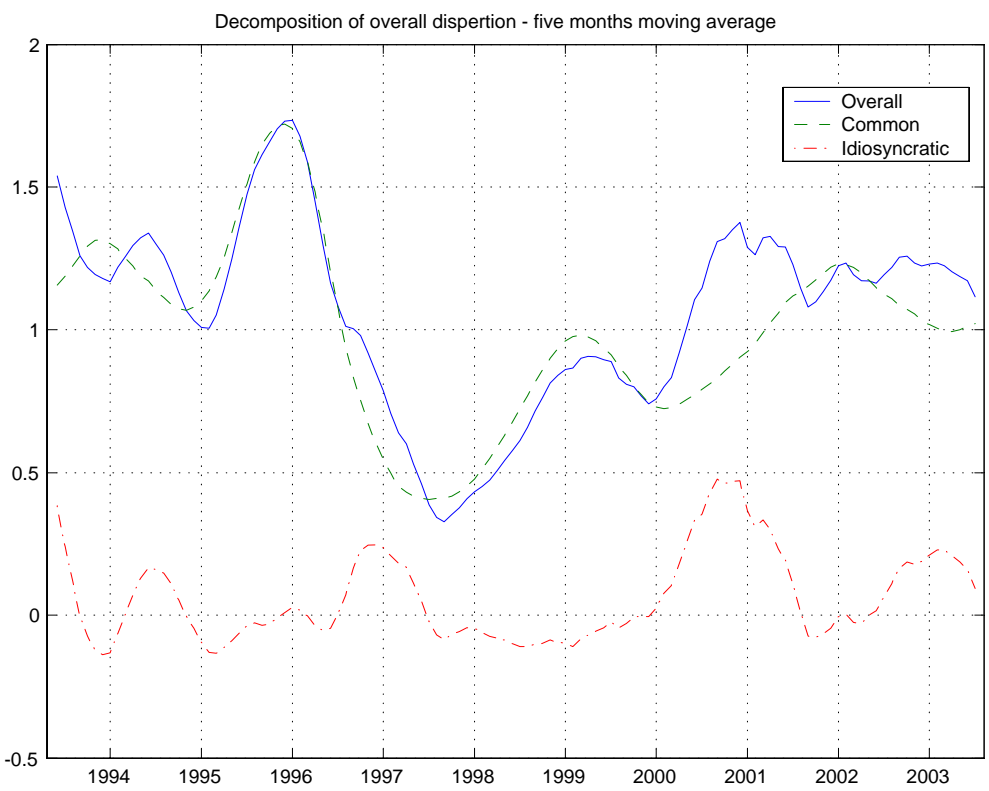

Fig. 4: Decomposition of Overall dispersion

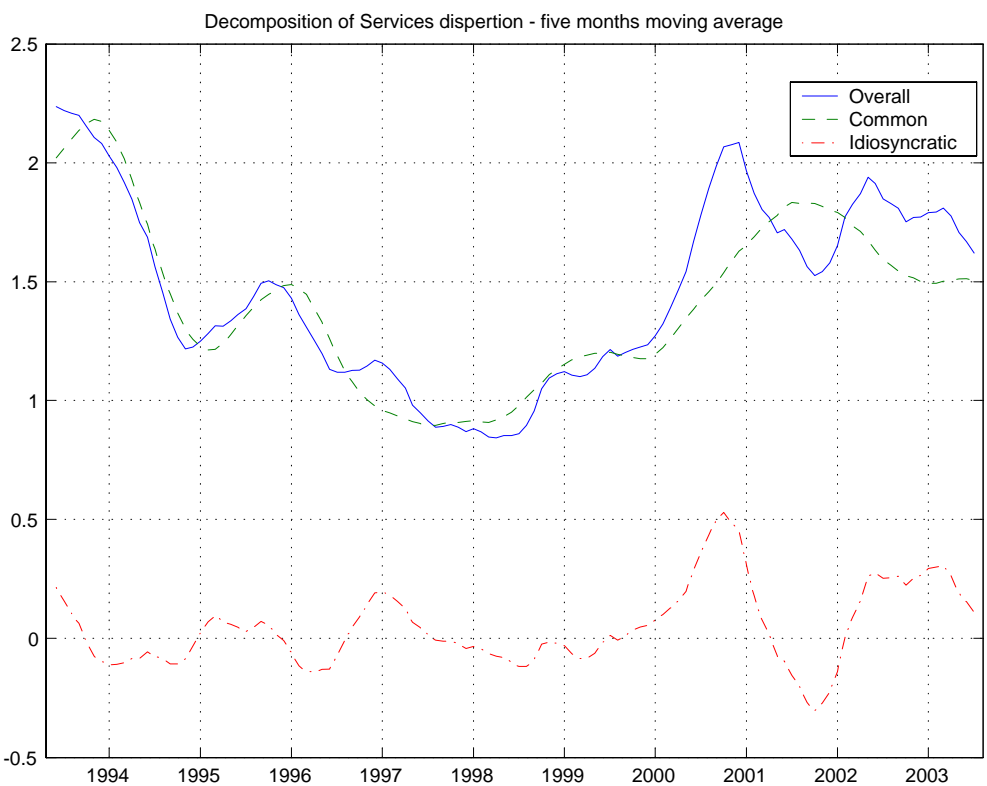

Fig. 5: Decomposition of Services dispersion 


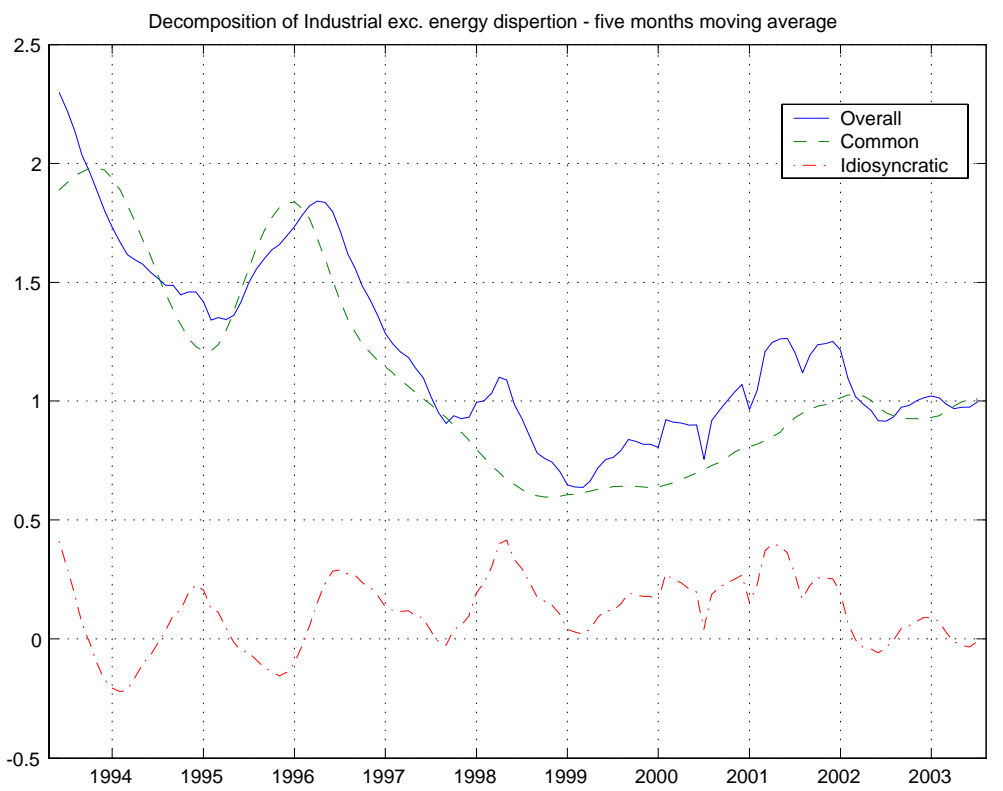

Fig. 6: Decomposition of Industrial Goods exc. energy dispersion

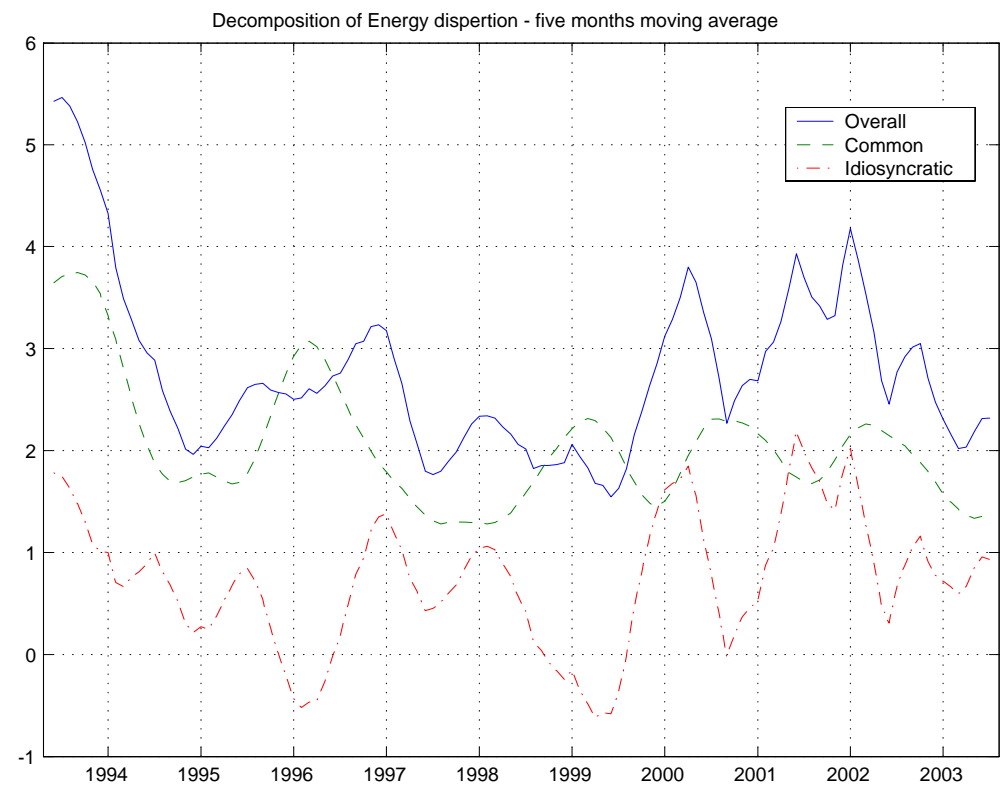

Fig. 7: Decomposition of Energy dispersion 